2011-06-28

\title{
Indigenous Women College Students' Perspectives on College, Work, and Family
}

Jennie L. Bingham

Brigham Young University - Provo

Follow this and additional works at: https://scholarsarchive.byu.edu/etd

Part of the Counseling Psychology Commons, and the Special Education and Teaching Commons

\section{BYU ScholarsArchive Citation}

Bingham, Jennie L., "Indigenous Women College Students' Perspectives on College, Work, and Family" (2011). Theses and Dissertations. 3038.

https://scholarsarchive.byu.edu/etd/3038

This Dissertation is brought to you for free and open access by BYU ScholarsArchive. It has been accepted for inclusion in Theses and Dissertations by an authorized administrator of BYU ScholarsArchive. For more information, please contact scholarsarchive@byu.edu, ellen_amatangelo@byu.edu. 
Indigenous Women College Students' Perspectives on College, Work, and Family

Jennie L. Bingham

A dissertation submitted to the faculty of

Brigham Young University

in partial fulfillment of the requirements for the degree of

Doctor of Philosophy

Aaron Jackson, Chair

Steven Smith

Rachel Crook-Lyon

Marleen Williams

Lane Fischer

Department of Counseling Psychology and Special Education

Brigham Young University

August 2011

Copyright (C) 2011 Jennie L. Bingham

All Rights Reserved 


\author{
ABSTRACT \\ Indigenous Women College Students’ Perspectives on College, Work, and Family \\ Jennie L. Bingham \\ Department of Counseling Psychology and Special Education, BYU \\ Doctor of Philosophy
}

Native American and First Nations (hereafter referred to as indigenous*) women college students are faced with a challenge to balance both their culture and the demands of the dominant Western culture in family, school, and work/employment roles. The presence of indigenous women in higher education and in the work force has increased since World War II. While there is an abundance of literature on work-family balance and work-family conflict, with some focus on the perspectives and expectations of college-aged students, there is a dearth in both of these areas with regards to indigenous populations. In order to begin to explore the experiences and perspectives of work and family, this study analyzed unstructured qualitative interviews of 11 Native American and 9 First Nations female college students. Themes resulting from the hermeneutic analysis of texts that describe the tensions around career, family and education were (a) honoring indigenous culture and community, (b) living in two worlds, (c) pursuing individual fulfillment and goals, and (d) acknowledging the importance and influence of family.

*Author's note: The term indigenous was used throughout the paper when referring to Native American and First Nations peoples as a group, as terminology used to refer to these specific groups differs in Canada and the United States. When cited research was group-specific, "Native American” or "First Nations" was used.

Keywords: indigenous populations, college students, multiculturalism, diversity in the workplace, sex roles 


\section{ACKNOWLEDGEMENTS}

This project could not have been completed without the travelers who joined me on my journey - sometimes leading, sometimes pushing, and sometimes just walking with me. I would like to thank my committee: Aaron Jackson, Steve Smith, Rachel Crook-Lyon, Marleen Williams, and Lane Fischer. Thank you for your support and flexibility, and for making this experience so enriching. I would like to give a special thanks to my chair, Aaron Jackson, for his guidance, patience, and encouragement. Thank you, Aaron, for believing in and expecting miracles. I have appreciated your guidance in research and throughout my training.

Sincerest thanks are due to the participants of this study. You and your stories affected me in a profound way, and I hope that my work can in at least a small way share your strength with others. I would also like to thank the many individuals who helped with logistics, motivation, ideas, faith, and time. This study would not have moved forward without the help of Quintina Adolpho, Carrie Fleischer, Lisa Fox, Colton Miller, Brian Parry, Caleb Bush, Louise Alexitch, and Jacob Jensen, and would not have been finished without the support of Melissa Bartsch (and her organized, figure-seeing brain), Connie Briscoe, Ashley Ross, and the rest of the Counseling Center staff at the University of Tennessee-Knoxville. And to Megan Marks, thank you for the hours, and hours, and hours of dissertation commiseration and encouragement.

From the deepest part of my heart, I would like to thank my family. Lance, thank you for all those years in Provo, and for making me smile. I miss you. Loralee, your faith and love have sustained me, and I have felt your prayers. Brian, thanks for being a model of a faithful scholar, brother, and friend. Mom and Dad, thank you for your constant encouragement, advice, and willingness to help. Finally, I would like to thank my Heavenly Father for the many miracles, for teaching me faith, for granting strength, and for answering the prayers of kind friends and family. 


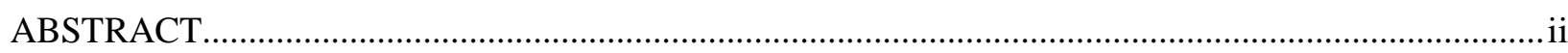

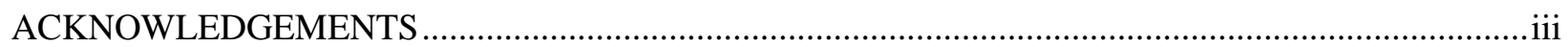

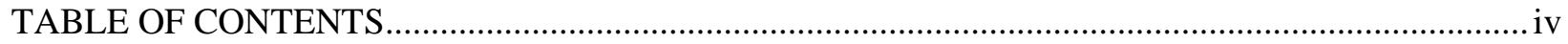

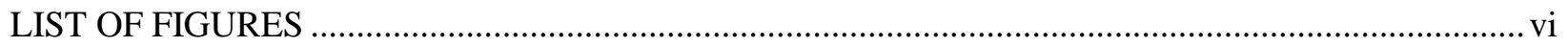

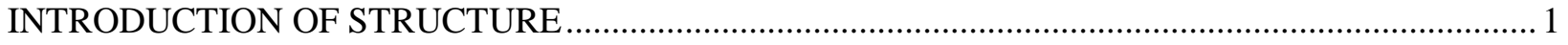

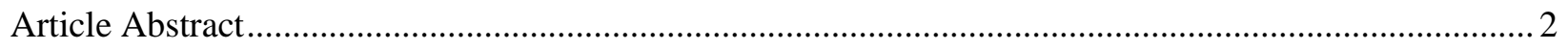

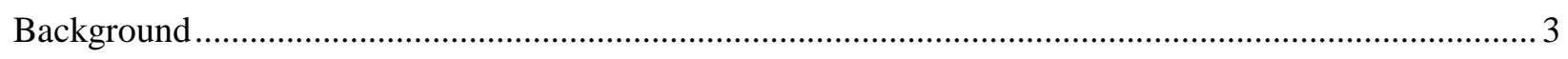

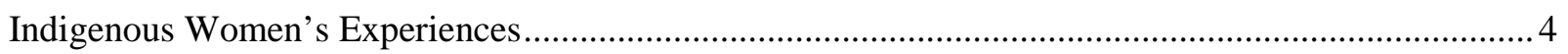

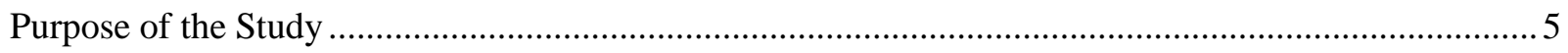

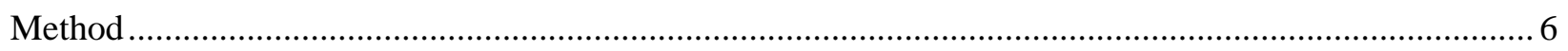

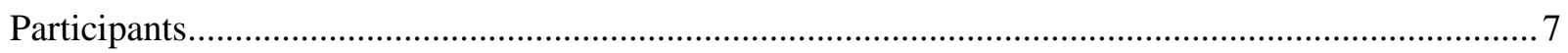

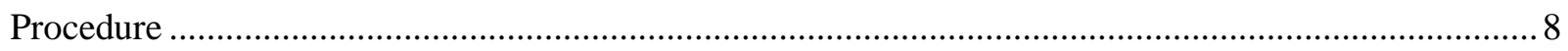

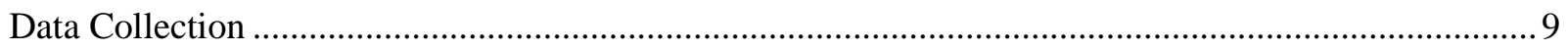

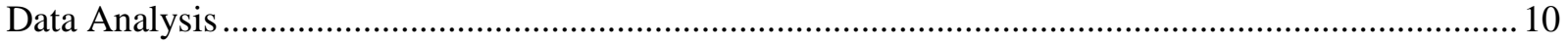

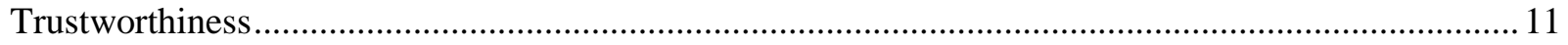

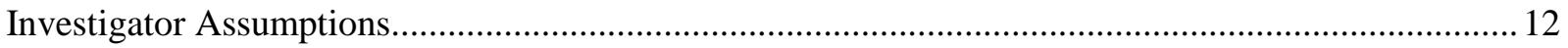

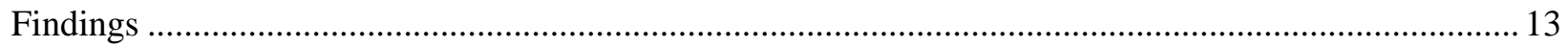

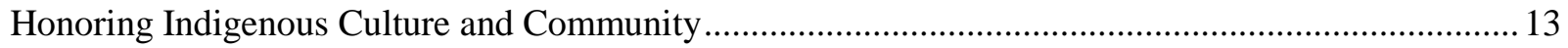

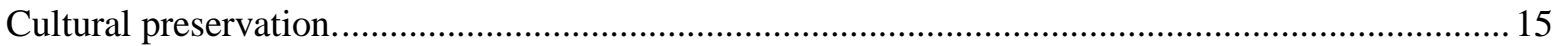

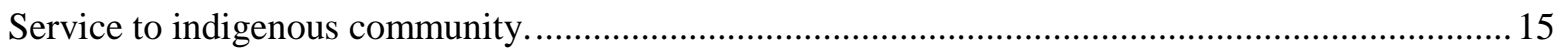

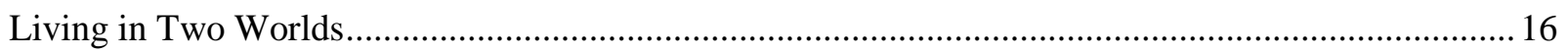

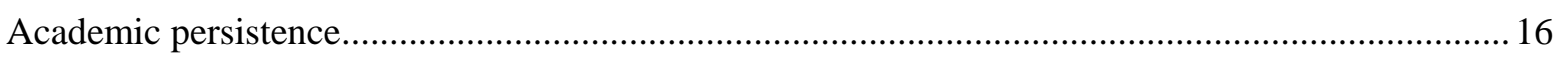

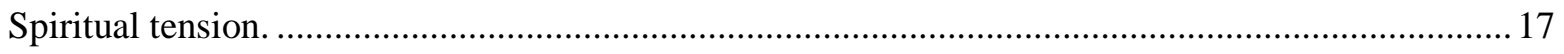

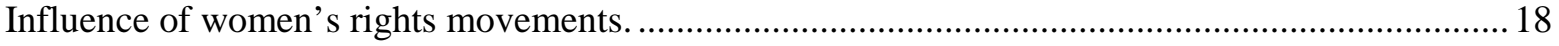

Pursing Individual Fulfillment and Goals ........................................................................................... 19

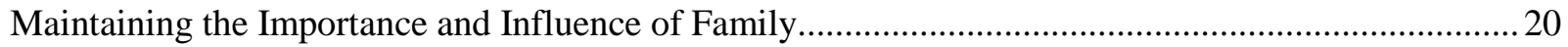

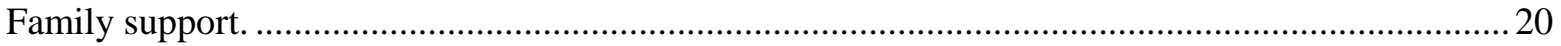

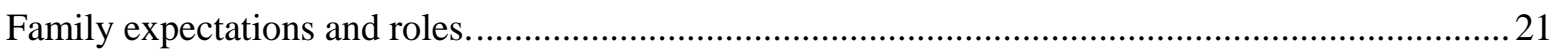

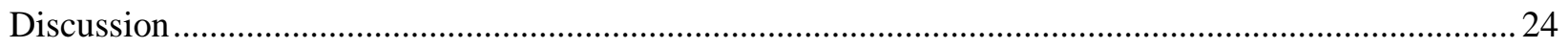

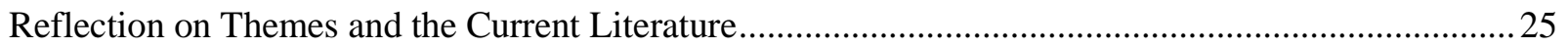

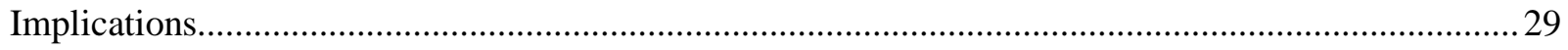




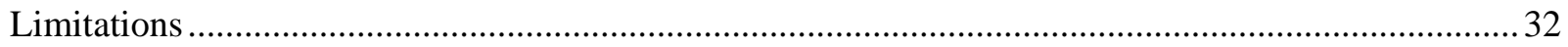

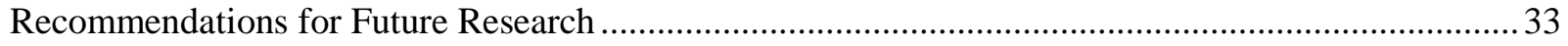

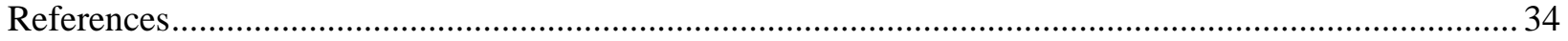

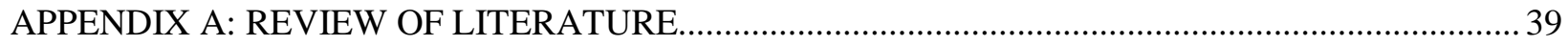

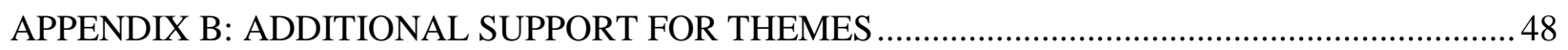

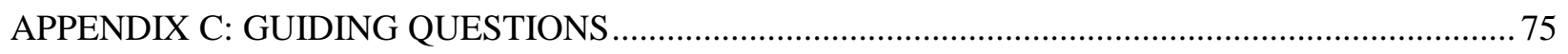

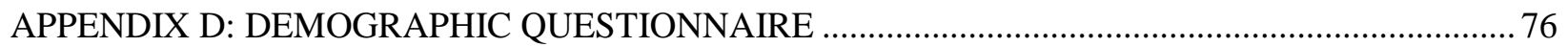

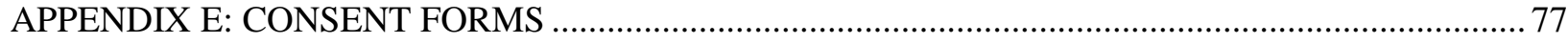

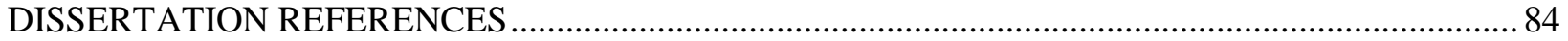




\section{LIST OF FIGURES}

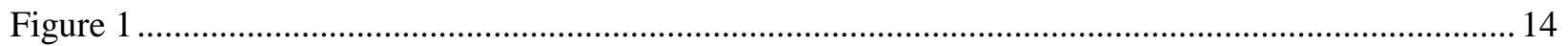




\section{INTRODUCTION OF STRUCTURE}

This dissertation, Indigenous Women College Students’ Perspectives on College, Work, and Family, is written in a hybrid format. This hybrid format combines traditional dissertation and journal publication layouts. The preliminary pages reflect requirements for submission to the university. The dissertation report is presented as a journal article and conforms to length and style requirements for submitting research reports to psychology and education journals. The literature review and additional support for the findings sections are included in Appendix A and $\mathrm{B}$ respectively. 


\section{Article Abstract}

Native American and First Nations (collectively referred to as indigenous) women college students are faced with a challenge to balance their traditional culture and the demands of the dominant Western culture. This is seen in decisions about family, school, and work/employment roles. While there is an abundance of literature investigating work-family balance and a growing interest in how the work-family balance affects college students, there is a dearth in both of these areas with regards to indigenous populations. In order to explore the experiences and perspectives of work, education, family, and culture, this study analyzed unstructured qualitative interviews of 11 Native American and 9 First Nations female college students. Themes resulting from the hermeneutic analysis of the interviews were (a) honoring indigenous culture and community, (b) living in two worlds, (c) pursuing individual fulfillment and goals, and (d) acknowledging the importance and influence of family. 


\section{Background}

Since WWII the number of women in the work force has increased, as has the presence of women on college campuses. Over the last few decades there has been a movement towards greater gender equalization in arenas that before the women's and civil rights movements were predominantly male. This movement has been accompanied by an increase in research exploring work and family balance. Over the last 25 years inquiry into the work and family interface has increased dramatically (Weer, Greenhaus, Colakoglu, \& Foley, (2006); Alfred P. Sloan Foundation [Sloan Foundation], 2008). Women made up 59\% of the labor force in 2009 (U.S. Bureau of Labor Statistics, p.12) and often perform a "second shift” (Johnson \& Johnson, 2008, p. 487), thus bearing the majority of the responsibility for household chores. This is a model that many of today's female college students have become familiar with as they prepare for careers.

College graduation has increasingly become an important ingredient in future career success. For many ethnic minority students, however, academic persistence rates are much lower than for those from majority backgrounds. This is true for Native American and First Nations students. For example, education achievement levels of Native Americans are lower than the general population. Only 9.3\% of Native Americans hold a bachelors degree or higher, as opposed to $20.3 \%$ of the general population (Jackson \& Turner, 2004). Mendelson (2004) reported that 60 percent of First Nations who lived on a reserve (aged 20 to 24) had not yet completed high school or obtained an alternative diploma. According to Statistics Canada and the 2006 census, 20\% of First Nations women aged 25 to 64 receive some sort of post-secondary training and only $9 \%$ obtained a university degree (Bachelor’s, Master’s, or Doctorate degree) (Milligan \& Bougie, 2009). In the same census, 23\% of women in the general population obtained a university degree (Milligan \& Bougie, 2009). Despite evidence of academic ability, 
postsecondary dropout rates are higher for Native American and First Nations students (hereafter referred to collectively as indigenous unless research is group-specific) than for any other minority (Freeman \& Fox, 2005; Mendelson, 2004; Reddy, 1993).

One way to explain the disparity in academic achievement is the demand placed on Native American students to adapt to a different culture when they pursue postsecondary education (Jackson, Smith \& Hill, 2003). In fact, Jackson, et al. (2003) found that successful Native American college students raised on reservations reported that getting through college required them to adapt to a different culture. However, these successful students kept a strong sense of their own culture. One obstacle to success in college for indigenous college students is the feeling that they must live in two worlds (Juntunen et al., 2001) - that of their culture and that of the "white campus" (Lin, LaCounte, \& Eder, 1988, p. 13).

\section{Indigenous Women's Experiences}

The transition to college may be even more difficult for indigenous women. Though information regarding career journeys for indigenous women is limited, Juntunen et al. (2001) attest to the lack of inclusion of indigenous participants in vocational studies and report that there is a skeptical view of career counseling held by many indigenous individuals. This skepticism may be due to cultural insensitivity on the part of counselors regarding the cultural values of indigenous people (cf. Bichsel \& Mallinckrodt, 2001). For example, community orientation and the importance of family are two values that heavily influence indigenous students' career and family decisions but may be less appreciated by mainstream career counselors (cf. Sue \& Sue, 1999).

The work of women within indigenous cultures is wide and varied. For example, indigenous participants in a study by Kawulich (2000) described work in four domains: home 
work (related to agricultural/rural upbringing, taught by female family members), public work (working outside of the home for pay), community/volunteer work (dancing, teaching language, and other projects where they could preserve the culture), and cultural/home jobs (crafts such as beading or metal work). Women are often responsible for a majority of the home-related work (Kawulich, 2000). In indigenous families women have complex, demanding roles, and the extended family (which often extends through the second cousin) shares responsibility for the education and raising of children (Sue \& Sue, 1999). For many indigenous cultures, “interrelationships between a large number of relatives are important, and there is a strong respect for elders and their wisdom and knowledge," and "life is to be lived in the here and now. Long-term plans such as going to college are seen as acts of egoism rather than future planning” (Sue \& Sue, 1999, p. 277). These cultural values may combine to make transition into college and the work force more difficult for indigenous women.

\section{Purpose of the Study}

Even with the awareness of the difficulty that indigenous women face as students and in the work force, there is little literature that focuses on what indigenous women college students believe or anticipate with regards to family and work. Given the well-documented struggles that many people face in balancing culture, work, and family life, a greater understanding of how indigenous women are preparing for, participating in, and thinking about the integration of these important areas may help illuminate the path these college students walk. Therefore, this study employed a qualitative method to explore the meaning, expectations, and experience of indigenous college women regarding family, work, and education. The purpose of this investigation was to gain increased understanding of indigenous women's experience as college students in an effort to further the development of culturally-sensitive career and personal 
counseling and to assist college personnel in bolstering academic persistence for these students. There were two main questions driving this study: 'What are the perspectives of indigenous women college students regarding work/career, education, and family?' and 'How do indigenous women’s cultural identities influence their career and familial plans/hopes?'

\section{Method}

This study investigated the lived experience, or "life world” (see Kvale \& Brinkmann, 2009, p. 29), of indigenous female college students regarding perceptions of college, work and family. It employed a qualitative analysis of unstructured interviews through successive readings of interview text using a hermeneutic circle, as outlined by Kvale and Brinkmann (2009). The philosophical foundation for the method of the study is a relational ontology (Schwandt, 2000). In other words, the fundamental assumption is that relationships are primary and necessary to understanding human experiences and that it is in the interaction between the interviewer and the interviewee that meaning is constituted. The epistemological foundation for the method is hermeneutic and dialectic (Denzin \& Lincoln, 2000).

In Gadamer's version of hermeneutic analysis understanding is seen as a "linguistic event” (Schwandt, 2007, p. 136) and as a way of understanding the phenomenological meaning of human existence. It is in dialogue or conversation with the individual and with the text of the interview that knowledge is found. A key tenet of this epistemology is that "understanding is something that is produced in [that] dialogue, not something reproduced by an interpreter through an analysis” (Schwandt, 2000, p. 195, italics in original). Meaning is not something that is constructed or created as much as it is negotiated “in a matter of coming to terms" (Schwandt, 2000, p. 195). The interviewer acts as the investigative tool in the process and enters into a dialogue with the participant through which meaning is produced. In keeping with this 
philosophy, the process incorporated Kvale and Brinkmann’s (2000) approach to interviewing, which is characterized by the following underpinnings:

1. Attention to the everyday "life world" of the participants.

2. Efforts to understand the meaning of the themes in the dialogue.

3. Dialogue aimed at qualitative rather than quantitative knowledge.

4. Encouragement of in-depth descriptions of the participants' experience.

5. Encouragement of descriptions of specific experiences.

6. A deliberate openness to novel and unexpected perspectives.

7. Focus on the phenomena of interest without using restrictive questions.

8. Acknowledgement of possible ambiguities and contradictions in the dialogue.

9. Awareness of new insights that may come to interviewer and participant in the interview.

10. Knowledge that each interviewer brings varying degrees of sensitivity to different aspects of the participants’ experiences and perspectives. (Adapted from Kvale and Brinkmann, 2009, pp. 28-32).

\section{Participants}

Participants in this study included 20 female college students who attended one of three four-year public college or universities located in Canada and the southwestern United States. Participants included indigenous women from three tribes (Navajo, Zuni, and Tohono O'odham) and one band (Cree). Participants had lived on or near a reservation or reserve for a majority of their lives (i.e. for at least 9 years before the age of 18). The women's ages ranged from 18 to 53, and experience in post-secondary education ranged from one semester to 7 years. Six of the 
women were single, eight were partnered, two were divorced, and one was widowed. The relationship status of three of the women was unknown. Eight of the participants had children.

Criteria for participation in the study were based on several assumptions. First of all, it was assumed that participants who had grown up on or near a reserve or reservation and had chosen to attend college would be engaged in the process of navigating the demands of living in two cultures (Jackson, Smith \& Hill, 2003). Participants were not limited to those who had only grown up on the reserve/reservation for several reasons. Individuals who have lived in the towns that surround the reserves and reservations (border towns) are assumed to have close friends and family members who live on the reservation or reserve and to be well-acquainted with their indigenous culture. In addition, it was assumed that individuals who grow up in border towns may constitute a large portion of indigenous students in university settings in the future, and their experience provides valuable insights for those who provide services to Native American and First Nations students. According to the 2006 Census, First Nations women who lived off of the reserve were more likely to have postsecondary credentials than those living on the reserves, and First Nations women were more likely to seek postsecondary education later in life (Milligan \& Bougie, 2009). Therefore, inclusion of participants of all ages was assumed to be valuable.

\section{Procedure}

Participants were recruited through contact with participating college personnel (faculty, indigenous center staff), classroom announcements and informal contact with the investigators. No compensation was provided for participation. After being given a brief overview of the purpose of the study and discussing informed consent, participants were asked to complete an informed consent form and a brief demographic questionnaire (see Appendices E and D, respectively). Confidentiality was enhanced by issuing each participant an identification code 
that was recorded on the demographic questionnaire in lieu of the participant's name. Interviews for this study took place on three campuses - two in the United States and one in Canada. Interviews were collected during one trip to each of the two geographical regions, with 11 participants being interviewed in the southwestern United States and 9 in Canada. Participant names were tied to their identification code only in instances where participants elected to provide their email addresses and consented to be contacted in the future to act as participantreviewers of the results of the study. After analysis was competed, all identifying information was destroyed.

\section{Data Collection}

Unstructured, qualitative interviews were conducted one-on-one and in person by the principle investigator and another female member of a qualitative research team. A list of guiding questions (see Appendix C) was used to assist interviewers to avoid leading questions and to maximize the depth and breadth of interviewee responses (Patton, 1990). Guiding questions were developed through collaboration with a research team familiar with Native American issues and by consulting the current literature. The initial set of guiding questions was tested in pilot interview. Then, over the first few interviews, the guiding questions were refined to better articulate and clarify their meaning. Interviews ranged from about 15 to 60 minutes in length and were audio recorded. Interviews were transcribed by a qualitative research team, which included the indigenous graduate student auditor. Each transcript was then interpreted by the principle investigator using a hermeneutic interpretive method (Gadamer, 2004; Kvale and Brinkmann, 2009; Kvale 1987; Packer, 1985; Polkinghorne, 1984, 1991). 


\section{Data Analysis}

The interpretation of the transcribed interviews subscribed to the same philosophical and theoretical assumptions as were used in conducting the interviews. The post-interview interpretive process is described below:

1. An unfocused overview of the text. The goal of this initial reading is to study the text with limited presuppositions and to begin to illuminate the meanings set forward in the interview dialogue (Jackson \& Patton, 1992; Kvale and Brinkmann, 2009).

2. Interpretations through successive readings. Using what has been called the hermeneutic circle, this is a process of engaging with the text at increasingly deeper levels by identifying themes and then circling back to the text searching for disconfirming statements. (Hoshmand, 1989; Kvale and Brinkmann, 2009; Polkinghorne, 1984).

3. Finding language to accurately convey meanings. Having compiled valid interpretations, (Kvale and Brinkmann, 2009), the final task is to strive to communicate the findings in a way that precisely represents the meanings and themes of the study. Following this process the primary investigator conducted several successive reviews of the transcripts in order to identify an initial set of themes. As the interviews were conducted in two countries with individuals who were primarily from two different indigenous groups, the initial stages of analysis were conducted on transcripts from each country separately. The preliminary themes from the two sets were compared and were judged to be consistent and complementary. Subsequent analysis was conducted on the whole body of interviews as a whole. This process of identifying meaning in a section or statement, and returning to the text looking 
for meanings that either confirms or disputes the identified theme is the essence of the hermeneutic circle. Jasper (2004) describes this process as follows:

In order to gain an overview of the text in its completeness, we must give proper attention to the details and particulars. But we cannot appreciate the details and particulars without a sense of the whole work.... Interpretation, therefore, is not a process along a linear trajectory from ignorance to understanding via the medium of the text (p. 21).

In addition to the analysis conducted by the principle investigator, a male graduate student trained in qualitative methods audited initial themes by conducting an independent, unfocused overview of four of the interviews (two from each country). The auditor identified initial themes and meaningful components similar to those that the principle investigator had identified. The principle investigator then continued to analyze the text. Themes that continued to be supported in successive readings of the transcripts were retained, and those that did not have broad support in successive readings of the transcripts were discarded. Once a coherent set of themes was defined the themes were evaluated by two theme auditors. One auditor was an indigenous graduate student from Canada who had participated in transcribing the original interviews. The other auditor was a non-indigenous Native Studies researcher from a large university in Canada. The auditors read a wide selection of quotations in order to determine whether or not there was sufficient evidence in the text and according to their experience to warrant inclusion of each theme.

\section{Trustworthiness}

The trustworthiness of the themes was enhanced in several ways throughout the study, primarily through the use of auditors. First, the trustworthiness of preliminary themes and of the principle investigator's process was assessed through consultation with an auditor who 
independently read four of the interviews and identified meaningful statements and preliminary themes. The meaningful statements and themes found by the auditor matched those that had been identified by the principal investigator. In addition, the trustworthiness of the final themes was assessed by two additional auditors, one from each geographical area of the study. Each auditor had extensive experience with indigenous students. Auditors were asked to comment on the veracity of the themes as per the text and their own experience with indigenous populations. The indigenous auditor (who transcribed a portion of the interviews but did not participate in the analysis of the text) verified that the themes were true to her experience as an indigenous woman. The non-indigenous auditor commented on groupings of themes and indicated that themes appeared consistent with her experience with indigenous research and students. The list of themes was finalized after receiving auditor feedback. The researchers attempted to include each of the three communities of validation Kvale and Brinkmann (2009) present (e.g. the interviewed subject, the general public, and the research community; p. 214). Researchers contacted participants who had consented at the time of the interview to review the findings but were unable to receive additional information from the participants.

\section{Investigator Assumptions}

There are several assumptions made by the principle investigator in this study. First and foremost, it was assumed that the western educational system has value for indigenous women, and that the pressures experienced by the women as students will be similar to the pressures they would experience in the work force. It was further assumed that students at the three institutions of higher learning were engaged in balancing their family life with their educations and employment. While it is possible that being in a different location during the interview (such as at the work place or on the reservation) may have produce different statements, it was assumed 
that by virtue of their role as students, interviewees were comfortable enough on a college campus to be self-reflective and frank in their comments. Methodologically speaking, it was assumed that qualitative interviewing is an effective way to create and understand meaning in the lives of indigenous women, and that said meaning will be beneficial in assisting educators, counselors, and the indigenous communities at large.

In addition, the principle investigator recognizes that the research questions guiding this study are influenced by her bias and experience as a single, Caucasian, female graduate student from a conservative background that places high value on family. While the particulars of the experience were expected to vary, it was assumed that women from an indigenous background would also experience tension between family and community/cultural expectations and educational and career goals. Finally, it was assumed that through the hermeneutic process and the use of auditors these biases and assumptions would not harm the trustworthiness of the results.

\section{Findings}

Analysis of participant interviews produced four primary themes, composed of seven secondary themes and seven tertiary themes (see Figure 1). Primary themes included (a) honoring indigenous culture and community, (b) living in two worlds, pursuing individual fulfillment and goals, and maintaining the importance and influence of family. These themes are interconnected, as will be evidenced in the participant quotes that support them.

\section{Honoring Indigenous Culture and Community}

A theme of honoring indigenous culture and community through (a) cultural preservation and (b) service to indigenous community emerged. Participants discussed varying levels of personal and familial cultural expression with an overarching community orientation. 


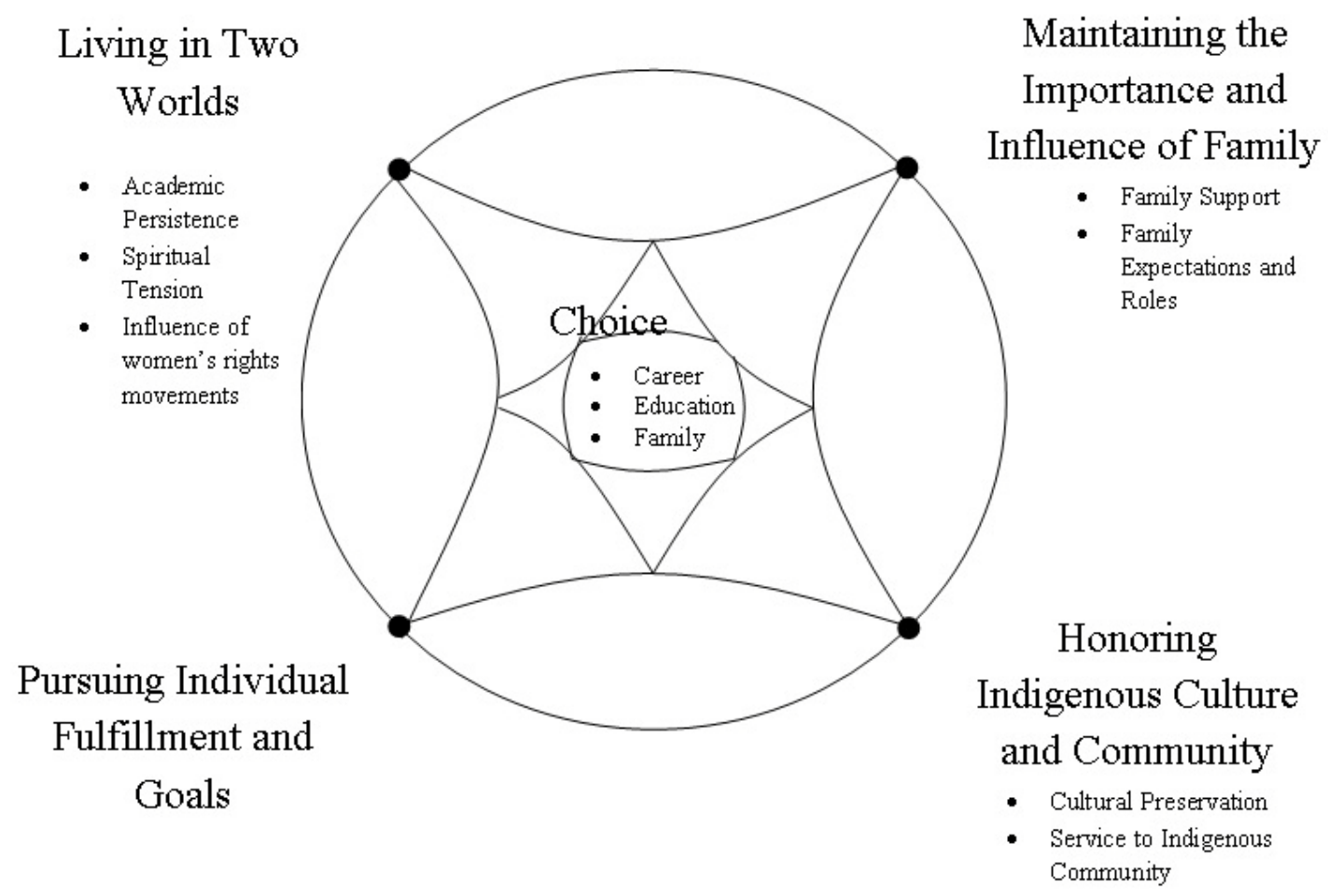

Figure 1. Indigenous women's choices about career, education, and family are informed by interconnected influences and tensions: family, personal goals, indigenous culture and community, and bicultural identity.

Participant 16: Being a Cree person and a Cree woman, you are supposed to know who you are and your culture.... I hate to say that when someone is Cree like me and they are a woman and they don't really know about tradition and or about powwow or anything, then I would think, “They aren’t really an Indian.”

In addition, participants discussed a loss of connection to their cultural communities as they transitioned into college as well as feeling strengthened through emotional and cultural support from their nation (i.e. indigenous student centers, members of the tribe/band "getting involved and actually keeping tabs on [them],” access to traditional cultural activities).

Participant 20: I used to dance and sing and everything, and now I don't do anything. And so I am going to start getting back into that. ...I lost myself when I came here. I am 
not me anymore - the way I would be when I was at home - and I do not like the way it feels. It feels like I have no culture....

Cultural preservation. Participants’ statements reflected a desire to pass indigenous spiritual traditions and language on to their children even if they themselves were not wellversed in the indigenous culture or had not yet decided to have children. This desire to preserve the indigenous culture motivated participants to want to return to the reserve/reservation after school and/or to live close to their extended families. Participant 4 stated, "I want to pass the whole package. I mean my grandparents and my parents they taught me everything. .... I want my kids to know all of that stuff...to teach their children and their grandchildren.”

Service to indigenous community. The commitment to the indigenous culture was also shown in a desire to be of service to the indigenous community. Participants discussed serving the community (a) as role models to other indigenous people and (b) through their career.

Serving as a role model. Getting an education was discussed as a way for participants to be role models to (a) family members of all ages, (b) indigenous children in the community, and (c) their current or future children. Participants discussed a desire to help indigenous youth avoid alcoholism, drugs, teen pregnancy, and other negative pressures by going to school:

Participant 4: Navajo children... when they see a young Native American go to school, you know they look up to you and they are like, "Oh I can do that, too. I can be successful like that too.” They can go ahead to change their life style and turn their life around to go in the right direction. ...Wow, I didn’t think that I could do all that! Participants also identified their own role models, and described receiving support and encouragement primarily from other women. 
Serving through career. Participants discussed pursuing a career that would be useful on the reserve/reservation and to the indigenous culture as a whole. The actual career path for some did not seem to be clearly defined, and participants discussed varying paths that move them towards an end-goal of a degree that helps the community. Participant 20 described her experience:

I just wanted to get my education so I could actually do something about what I see like at home. Make a difference at home. Why go somewhere else and try to make a difference where you don’t even know anybody? It just means a lot more when you grew up with people...it will just be different. You'll feel really cool... Not only [making a difference in] their lives but in the community.

\section{Living in Two Worlds}

Participants described a perceived requirement to be proficient in both their indigenous culture and the broader culture of Canada and the United States (often described by participants as the "white" world). A theme of walking between the indigenous and the dominant cultures and living in two worlds arose as participants were growing up and transitioning into college. Participant 11 highlighted this when she said, “...it’s become more contemporary towards the modern life because we have basically two things to do - our traditional ways and the ways of the world around us.” The degree of biculturalism varied among participants and within their families. This theme is described through (a) academic persistence, (b) spiritual tension and (c) the impact of women's rights movements.

Academic persistence. Participants identified a central goal of finishing college, and advised other indigenous women to persist in their academic pursuits. One participant said, 
Participant 9: I try and encourage them [other students] that way ...stay in school. It will be worth it in the long run, and I think at one point that's what people had to tell me - it will be worth it in the long run - so I keep telling myself that especially the days when I get really discouraged....

The women described their transition into college as being difficult at times, and many mentioned watching family members and friends drop out. Family responsibilities, having children, the loss of cultural and family connection, and finances were identified as factors that affect persistence.

Spiritual tension. Participants discussed feeling a spiritual tension that resulted as they tried to balance the "conflict” between traditional spiritual beliefs and dominant religious and secular thought. Participant 16 stated, "Balancing the spiritual part - the Cree - and the education is really hard because there is no room for spirituality in education. There's nothing, so they don’t mesh together. Combining those two is hard.”

Reactions to the spiritual tension varied widely. For example, while some participants discussed participating in both Christianity and indigenous spiritual traditions, considering them to be "the same thing,” others expressed confusion with respect to spirituality. Participant 17 discussed the difficulty that arose for her after learning about the history of her indigenous people and the way her people had been treated by Christians. She said,

I took some native studies courses... and they just really broke my heart....So, ever since then I've just been really, really iffy about all the religions. I'm not atheist. I do believe that there's a greater power out there. I just...getting in touch with the right power is my problem. 
Influence of women's rights movements. A theme reflecting the influence of women's rights movements emerged as participants discussed (a) shifting roles of women and (b) advocacy. This theme references the interface between the roles of women in indigenous and dominant culture, as well as the interaction of indigenous peoples with the dominant culture at large.

Shifting roles of women. Participants discussed generational shifts in female roles. With each generation, the women described respect for traditional gender roles as well as increased acceptability and support for women to explore career options, pursue an education, and seek a voice and empowerment in public. They also described shifts in the women's expectations regarding the division of traditionally gender-specific home and family tasks.

Participant 9: ... I talk to [my granddaughters] a lot about how important it is to stay in school and... just have fun as long as they can. I talked to their dad, “Don’t make women out of them even though they are at that age. Even though the tradition says this is automatic, and this is automatic, and this is what happens. Let them play their sports. Let them have their friends. Let them be out there and let them get involved with things,” I said, "but still keep them close...and they will be alright."

Advocacy. Participants also discussed gaining an education within the dominant culture in order to gain a stronger voice, a sense of empowerment, and credibility. One participant said, Participant 15: I think the only other way to make a big change...is by coming here and grabbing my degree or another two degrees and going back and saying, 'Look! I am not just a bantering idiot at membership meeting; you have to listen to me!'

The theme of advocacy was seen in participants' desire to speak up for themselves - to "find the advocate you need inside" - and for their indigenous community in response to 
perceived racism and sexism. Participant 14 stated, “At times I try to prove myself - that I can work no matter my skin color. ... I've got to be able to show them that we, as a whole, women can work; Aboriginal women can work.” Participants also discussed efforts to improve the dominant cultures’ perception of indigenous peoples. Participant 4 said, “...this is where we come in - to teach them that we are modern people, too. ... Informing them gives them the knowledge to not judge how they [individuals on the reservation] live or how they look.” Participant comments reflected both a movement towards a more solid indigenous identity and a down-playing of indigenous identity in response to prejudice and discrimination from both dominant and indigenous cultures. Gender-based discrimination seemed as - if not more - salient as racial discrimination in the lives of the women.

\section{Pursing Individual Fulfillment and Goals}

The theme of pursuing individual fulfillment and goals addressed the participants’ decisions to gain an education and pursue careers for personal improvement and fulfillment. Participants identified college as something that enriched the self while allowing them to be more effective in helping others in the community. While participants discussed the individual nature of their goals, priority was often placed on family and community. Participants distinguished a “career” from having “job” (i.e. having a career implied enjoying work as opposed to working just to have employment) and identified college as a way to find a career. Participant 17: It's like the dream come true. Being a little kid and always driving by the university, I always wondered what it would be like to actually be a university student. And now that I'm here...it makes me feel a sense of accomplishment that I actually did something great with... what I'm going to be. 


\section{Maintaining the Importance and Influence of Family}

The importance and influence of family (broadly defined by participants as blood relatives, adopted relatives, and family friends) was a major theme throughout the interviews. Family was identified as the most important priority. Participant 6 reflected this value:

... I am always going to want to come home, even though money can be important, too. But, like my dad always says, your family is more important than money. Money comes and goes but family doesn't so that's why it is important.

Individual family members and dedication to family heavily influenced participants' decisions about partnering, having children, forming a career, and pursuing an education. Participants' comments reflected that the "traditional” way was to put family "first,” and some participants stated that pursuing a career at the expense of having children felt selfish. Analysis of participant comments produced two secondary themes: (a) family support and (b) family expectations and roles.

Family support. Family was identified as the most influential support system in participants’ lives, as was illustrated by participant 9:

I think it is important ...to know that your family supports you. For a long time I [thought] that I was doing this on my own...and it took me a while to realize that they missed me, too, and they loved me. I know that I have their support. ... now I see how much they miss me and that encourages me to keep on doing what I am doing so that I can hurry up and go home. That is a big thing - to feel that support from my family. This support was discussed as influential in participants' transition to college, ability to persist in college, and success in balancing the demands of student life with the demands of family life. Participants identified specific ways in which family had or had not supported 
academic pursuits, and, at times, identified a lack of support as motivation to work hard and prove that they could be successful.

Family expectations and roles. In addition to the support that family provided, participants addressed family influence regarding (a) expectations for career/education, (b) gender-based roles and expectations, and (c) balancing roles and expectations for family, school, and career.

Expectations for career and education. Family expectations for career and education were influential in participants' education and career paths. Working outside of the home in the future seemed to be expected, and family attitudes about education and employment influenced whether or not participants attended college as part of their preparation for work. When asked what motivated her to come to college, participant 13 stated,

I guess my parents, mostly my mom because...education was important to them and so they saw people that lived on the reserve who didn’t really have an education and didn’t really have like I guess, a way of supporting themselves. ... She wanted us to have an education and then get a good job so we would be like financially stable for our kids. Positive family messages about college motivated participants to work hard in school and not let the family down, and provided support in balancing family and scholastic demands. Family messages that did not overtly supportive college attendance were also noted as participants described indirect paths into college and family members' skepticism in the face of the need to provide for children. When asked how her family felt about her attending college, participant 3 said,

At first they didn't like it. They thought I should just work and provide for my kids. But after a while they began to realize, "maybe she is doing it the right way.” And now they 
don’t say anything to me, not anymore. They don’t bother me. They just more help me more even more now.

Gender-based roles and expectations. Participants discussed traditional gender-based roles within the family. The degree to which families adhered to traditional roles varied widely within the same family and across generations. Participants described a division of male and female responsibilities at home (i.e. female roles traditionally included preparing food, taking care of children, cleaning the house, and doing laundry; male roles included taking care of the home’s surroundings, constructing/building objects). In addition, participants classified their family roles by relationships (i.e. mother, sister, aunt, grandmother, daughter, wife) and by actions (i.e. nurturer, role model, advice-giver). Participant 4 described an example of these roles:

...the main thing is to be there once you have kids, to provide for your children, to be there to show love to your kids and to teach them the culture and the values... and being there for your...spouse and to provide that support for them. I think those are pretty much the things I learned from my grandparents and my mom.

Participants discussed filling gender-based roles early in adolescence, such as helping raise younger siblings and cousins. Participants also referred to an expectation for them to form families of their own. Participant 7 described some of the stress that this expectation placed on her:

I am still not ready [to have children]. I just freak out when people talk about it - like family. Because I got married it seems like they have this pressure on me like I am going to have kids or something. It is kind of hard, but I think they kind of understand now that 
I have explained...to them...how hard it is. I am not ready for that...they don't bug me about that any more after I made clear to them that I am not.

Balancing roles and expectations for family, school, and career. The tension between the multiple roles that participants fill was reflected in a desire to give time and support to family while focusing on school. The tension that the women discussed seemed to reflect their community’s desire for them to be successful in school and work while also fulfilling their family roles. Participant 2 verbalized this tension:

You know what? Come to think of it right now, I actually fill both roles - my own role, where I don't have to stay home... where I can still go to school and strive towards what I wanted at the beginning, and still be what he wants...his laundry, cooking, and that [kind of] thing. So I've looked at both roles at the same time. On the weekends or whenever I feel like I need to have help, I tell him, "You know, you need to do some of this and some of that." ...But, at the same time, my mom tells me, "You know, women are supposed to do these things.” So, come to think of it, I do. I fill both roles. That's why it's kind of overwhelming sometimes.

Participants discussed balancing these roles in by both mentally separating responsibilities (e.g. focus solely on school while at school and on family when at home) and trying to combine family and education (e.g. work on homework while spending time with family).

Participants defined successful careers as those that allowed them to be home with family in the evenings and on weekends. This process reflected an expectation to put family first. For participants who were partnered, the balancing of roles and expectations was complicated by the need to reconcile differing expectations of in-laws, partners, and families of origin with respect 
to the practice of indigenous and dominant cultures in the home. These decisions involved parenting, the division of domestic duties, spirituality, education, and career. For partnered and single participants, having children affected the expectations placed on participants’ role balance. Participant 4 described these expectations when she said,

Participant 4: You can do whatever you want. Just know that if you want a career and go to school that's good, that's ok, but...our expectation is to provide nourishment to our kids and then to have two different roles: as a mother and to continue our careers in what we want to do.

Children were seen as both restricting freedom and as the most important part of participants' lives, and participants consistently advised others to wait to have kids until after college in order to make it easier to be successful in both family and education.

\section{Discussion}

Indigenous women college students’ life decisions and experiences are greatly influenced by a combination of cultural and familial factors. This study used a qualitative method to explore the experience of indigenous female college students. Decisions that indigenous women college students make about education, family, and career seem to be based in a fluid bicultural, familyoriented identity (see figure 1). Participants discussed their experiences in an interconnected, holistic fashion. This was reflected in them themes that emerged, which built upon and mutually influenced each other. Prominent themes that arose included (a) honoring indigenous culture and community, (b) walking in two worlds, (d) pursuing individual fulfillment and goals, and (e) maintaining the importance and influence of family. The following sections will discuss the findings in light of the current body of literature, highlight implications of the results, review the limitations of the study, and provide suggestions for future research. 


\section{Reflection on Themes and the Current Literature}

Themes that emerged from this study both support and build upon the current body of research. Like Kawulich (2000) reported, this study found that education is seen as desirable and helpful for many indigenous students. As was found by Juntunen et al. (2001) and Jackson \& Smith (2001), indigenous students in the present study described attending college as a bicultural experience in which they are expected to be well-versed in both indigenous and dominant cultures. A connection to the indigenous culture was found to be helpful (Kawulich, 2000; Juntunen et al., 2001). This connection was identified as support received from the indigenous community through encouragement, funding, traditional spiritual ceremonies, and connection to other indigenous students and leaders through Native American and Aboriginal Student Centers. Participants also described feeling a sense of purpose through pursuing careers that would allow them to give back to their indigenous communities and through being role models for other indigenous people. Participants also identified a tension between indigenous spiritual traditions and the dominant culture’s main religion, Christianity.

Previous studies have documented that some students experience a paradoxical cultural pressure to both gain an education and maintain their cultural identity (Jackson, Smith \& Hill, 2003; Kawulich, 2000). Results from the present study indicate a further paradoxical pressure to gain an education and maintain a cultural identity while at the same time fulfilling specific gender roles and expectations. These expectations include forming a family, being available to their immediate and extended family, and performing the vast majority of household work. This paradox underscores the expressed tension in prioritizing school, work, and family life, and was discussed by participants when addressing issues of academic persistence, career choice, and interactions with family. 
In describing a portion of this paradoxical pressure, participants stated that they had been advised by family and friends to wait to have children until after receiving their education. Participants passed this advice on to other women regardless of the participant's own situation. However, family members' advice shifted when participants had children; children were then described as the most important priority and college being acceptable as long as the needs of the partner (when applicable) and children were met. This idea was further supported by comments of indigenous women who had returned to school after their children were grown. At that time it became more acceptable for the women to go back to school and "do something for themselves" as the children no longer needing as much care and attention. Education then seemed to become more for the fulfillment of the individual. This may be part of why First Nations women tend to receive post-secondary credentials later in life (i.e. ages 35-54) than their non-indigenous counterparts (Milligan and Bougie, 2009). However, women who had returned to school after raising children continued to discuss the pull of family as they mentioned feeling sadness and guilt for not being around their grandchildren and teaching them about their indigenous culture.

The guilt expressed by students was one example of the stress that can result from the work-family conflict. Parker and Aldwin (1994) stated that the degree to which work-family conflict causes distress for women students of all ages may depend on how much value the individual student places on education/career with less stress occurring when women placed high value on career. While commitment to education and career varied, many of the participants in the current study placed a higher value on family than school/career. According to Parker and Aldwin's (1994) findings, this may indicate greater likelihood for stress in balancing school and family for indigenous women. This finding was not limited to women who had children, as those 
who had not yet formed a family discussed their stress in their relationships with their families of origin as they participated in school.

The school-family conflict was reported as being stressful for indigenous women college students, but the current study also indicates that family support and interactions provide important strength and motivation for the students (c.f. Napholz, 2000). Family support assisted individuals in fulfilling family responsibilities and in academic persistence. This support was felt through words of encouragement, time together, a sense of making others proud, and the provision of childcare. The influence of family was widely felt even when family members expressed doubt that the participants could be successful in school. Participants cited the lack of encouragement as an impetus to work harder, graduate, and prove that they could successfully balance family and scholastic demands.

Navigating the tension between school and family was complicated by the need to live in two worlds - those of the indigenous and dominant cultures. Therefore, the women were engaged in balancing the values that the two cultures place on women's engagement in work and schooling in addition to the expected tasks of balancing how they use their time and energy. The shifts in gender-based expectations in the dominant culture through movements such as feminism, civil, and women’s rights (c.f. Heer \& Grossbard-Shechtman, 1981; Rudy, Popova, \& Linz, 2010) were mirrored in participants' discussion of shifts in gender-based expectations within the indigenous culture. The influence of feminism was seen in the requests for a more egalitarian division of gender-based family roles as well as in the tension that individuals experienced as they balanced individual goals and family expectations for career and education. While participants voiced a desire for more equality in decision-making and performance of household chores the general expectation that women are mainly responsible for household 
duties seemed to still apply. When the women discussed boyfriends', husbands', or fathers' participation in household demands in an effort to support the woman's education or employment demands it was often discussed in a way that indicated that the woman has ownership of those duties and that the man's assistance was not expected. For participants who reported growing up in a home where the division of household duties (i.e. making bread, cleaning, watching children) was more egalitarian, the task of negotiating the division of household duties was complicated by in-laws’ gender role expectations.

Generational shifts in the roles of women were seen outside of the home as well. The last 50 years have seen a marked increase in the inclusion of women in the workforce (Weer, Greenhaus, Colakoglu, \& Foley, (2006); Alfred P. Sloan Foundation [Sloan Foundation], 2008). Participants discussed employment outside of the home as if it were expected. The women described education as a difficult yet fulfilling option, but employment was not discussed as a choice. In fact, the option of being a stay at home mom was not mentioned by participants in this study. However, the quality of work was addressed. Participants identified college as a way to have a career that was enjoyable and meaningful and to secure a 9 to 5 schedule that would allow them to be home with their family. Having a career and a family was at times discussed as being mutually exclusive regardless of the relationship status of the individual. This seemed to be due to the priority that the participants and their families placed on being home with the family. In other words, working a less-than-meaningful job that allowed the individual to be at home with the family was seen as more "traditional” and compatible with meeting family responsibilities than pursuing interest in a career that required extensive travel or time away from home.

The effects of cultural shifts towards equality are also seen in the development of a bicultural identity and in participant's efforts to find a voice within their bicultural identity. For 
college students in general, effort that may feel self-focused is often required. This may be difficult for indigenous students who may think from a collectivistic worldview. One resolution of the bicultural tension between the value of individualism within the dominant culture and value of collectivism within the indigenous culture is seen in participants viewing education as something that is for the betterment of the community or family. The tendency to work towards the betterment of the community is a reflection of the deeply-held commitment that the individuals have to their indigenous culture and may be a way to resolve the cognitive dissonance that may result from working towards goals that can feel "selfish,” such as school work and professional pursuits (c.f. Sue \& Sue 1999). Through this viewpoint, the individual is able to meet personal goals as they work towards a collectivistic goal. This was also illustrated by the theme of advocacy in that the women attended university to gain voice and empowerment which they then intended to use to help the indigenous community.

\section{Implications}

As has been mentioned, individuals who come into contact with another culture vary in how they construct their ethnic identity and in how much of the second culture they chose to commit to in behavior, norms, and values (Bichsel \& Mallinckrodt, 2001). This is true for the indigenous college student and for the family or support system by which they are raised. Therefore, it cannot be assumed that each indigenous student will face the exact same pressure or balance the expectations for career, culture, and family in the same way. However, understanding that there is a multi-layered constellation of factors that influence these indigenous women may assist college personnel, counselors, and career advisers better know which questions to ask in order to better understand the needs, goals, and decisions of the individual with whom they are working. 
Facilitating the students' connection to their indigenous culture is highly recommended. As has been mentioned in the literature (c.f. Thomason, 1999), provision of a Native American or Aboriginal (First Nations) Student Center has been paramount in assisting students in both their transition to the college or university and in providing the cultural support and connection that participants identified as crucial in fostering academic persistence. This support is augmented by the presence of elders from local bands and tribes. Furthermore, this study suggests that another critical support may be facilitating contact with indigenous women who can act as role models for students, including women who actively balance career and family responsibilities. This might be accomplished by including the employment of indigenous women in the center in various capacities, inviting women from the community to participate in workshops, or through structured outreach programs such as job shadowing. In addition to providing opportunities for indigenous women students to interact with indigenous professionals, colleges may find it beneficial to design programs that connect students with opportunities to be of service to indigenous communities.

This study also provides valuable information for career counselors. The provision of career counseling may assist indigenous women in clarifying career and educational goals and identifying or broadening career options given the value of family. For career counselors, it may be important to assist the individual in identifying the goals that she has set for both family and career. It may be that, as was seen with many of the individuals in the present study, career goals are vague and may not be clearly tied to the course of study that the individual is currently pursuing. Furthermore, if an individual is motivated by a desire to help the community from which she comes, it may be helpful to explore both the aptitude and interests of the student and assist her in identifying ways in which her particular strengths can be utilized. Traditional 
assessments alone may not paint a full picture for the student or for the career counselor (McCloskey \& Mintz, 2005), as was identified by one participant whose aptitude and career tests suggested a career in engineering but was pursuing a career in social work in order to provide direct service to her community. In addition, it is important that career counselors and other faculty and staff not assume that a student's indigenous identity has led her to choose her family as the most important priority in her life.

Implications for personal counselors from the present study are equally important. As is true for college students from multiple backgrounds, indigenous women are in the process of negotiating their identity as either an emerging adult or non-traditional student (Jones \& McEwen, 2000). While these students will be similar to non-indigenous students in many ways, it may be helpful to keep in mind the priority and value that may be placed on family - both family of origin and on forming a family - as well as the varying degrees of biculturalism that the student, their family, and possible in-laws may hold. It is also important to recognize that women who do not have children of their own may still be filling the role of a care-taker for younger siblings, cousins, etc. (Sue \& Sue, 1999). With relatively few role models to guide them, indigenous students are faced with reconciling the values of receiving an education, carrying on indigenous traditions, and performing the majority of household and family-related duties. These students may feel the pressure to do and be everything for their families and for their culture. It may be helpful for counselors to assist the student in exploring roles that they currently fill, those they anticipate filling in the future, and those that they may experience as competing (c.f. McCloskey \& Mintz, 2005).

In addition to exploring the roles that indigenous women fill, assisting the student to identify which values within the indigenous and dominant cultures seem to compete and ways 
that they themselves would like to reconcile the tension may also be helpful. For example, the role of spirituality and indigenous tradition in the student's life may be an important aspect of the student's identity. The counselor's demonstration of cultural competence, respect, and openness to the integration of spirituality in the student's life will help establish necessary trust (Trujillo, 2000). In addition, exploration of the interplay of individualistic and collectivistic goals may be helpful. While the dominant culture often places importance on putting the individual first in decision-making about majors and careers this practice may not be culturally sensitive to individuals whose cultural values place more importance on a collectivistic basis for decisionmaking (Sue \& Sue, 1999). However, recognizing that participants in this study discussed college as a place to gain a voice, exploration of how the student prioritizes self, family, and cultural voices in the decision-making process would be appropriate.

\section{Limitations}

There are limitations of the current study. First of all, while interviews can be expected to vary in length and depth of content, it appeared that the interviews conducted by the indigenous member of the research team tended to be richer in cultural data than those conducted by the non-indigenous principal researcher. It is possible that the interviewees felt more comfortable discussing traditional values, roles, and influences with the indigenous researcher. This may have contributed to the differing lengths and depth of interviews. While the auditors substantiated the themes, the researchers were unable to reach participants to perform member checks that could have further substantiated the findings of the study.

Additional limitations may have resulted from the location of the interviews and the nature of the interview questions. With respect to location, some interviews were conducted in indigenous student centers and others were conducted in separate rooms. It is possible that 
having conducted the research on campuses could have affected the information that participants were willing to share. Finally, while none of the participants identified as gay, lesbian, bisexual, or two-spirited, the study's purpose and questions may have been perceived as heterosexually oriented and thus limited its ability to access the experiences of GLBT indigenous students.

\section{Recommendations for Future Research}

This study both confirmed findings of existing research and lends direction for further inquiry into indigenous women’s experiences of family, school, and work. As was mentioned, participants identified some effects of feminism and a movement towards equalization of gender roles within indigenous cultures. Further studies are needed to investigate models of career counseling; employment trends; the integration of cultural content on campuses; and the relationship between the strength of bicultural identity, the expression of traditional spirituality, and satisfaction in decisions made about career, education, and family. Additional studies exploring the experience of family members of female indigenous college students may also be beneficial in that they could allow for greater understanding of the community's expectations and available resources with respect to supporting students in the college experience. Furthermore, many participants expressed interest in using their degrees to build their communities on the reservation/reserve. However, many of these graduates do not actually end up working long-term on the reserves/reservations (Milligan \& Bougie, 2006). Follow-up studies that investigate factors playing into college graduates' decisions about where to live and work would be valuable. Finally, there is a need for future research that inquires after the lived experience of indigenous individuals who do not identify as heterosexual. 


\section{References}

Alfred P. Sloan Foundation. (2008). Workplace, workforce, and working families: History. Retrieved from http://www.sloan.org/program/32/page/84

Bichsel, R. J., \& Mallinckrodt, B. (2001). Cultural commitment and the counseling preferences and counselor perceptions of Native American women. The Counseling Psychologist, 29(6), 858-881. doi:10.1177/0011000001296007.

Denzin, N. K., \& Lincoln, Y. S. (2000). The discipline and practice of qualitative research. In N. K. Denzin \& Y. S. Lincoln (Eds.), Handbook of qualitative research (2nd ed., pp. 1-29). Thousand Oaks, CA: Sage.

Freeman, C. \& Fox, M. (2005). Status and trends in the education of American Indians and Alaska Natives (NCES 2005-108). U.S. Department of Education, National Center for Education Statistics. Washington, DC: U.S. Government Printing Office.

Gadamer, H. G. (2004). Truth and method. New York: Seabury Press.

Heer, D. M., \& Grossbard-Shechtman, A. (1981). The impact of the female marriage squeeze and the contraceptive revolution on sex roles and the Women's Liberation Movement in the United States, 1960 to 1975. Journal of Marriage \& the Family, 43(2), 49-65. doi:10.2307/351416

Hoshmand, L. T. (1989). Alternate research paradigms: A review and teaching proposal. The Counseling Psychologist, 17(1), 3-79. doi:10.1177/0011000089171001

Jackson, A. P., \& Smith, S. A. (2001). Postsecondary transitions among Navajo Indians. Journal of American Indian Education, 40(2), 28-47. 
Jackson, A. P., Smith, S. A., \& Hill, C. L. (2003). Academic Persistence Among Native American College Students. Journal of College Student Development, 44(4), 548-565. doi:10.1353/csd.2003.0039

Jackson, A. P., \& Patton, M. J. (1992). A hermeneutic approach to the study of values in counseling. Counseling and Values, 36(3), 201-209. Retrieved from EBSCOhost.

Jackson, A. P., \& Turner, S. (2004). Counseling and psychotherapy with Native Americans. In T. Smith (Ed.), Practicing multiculturalism. Boston: Allyn Bacon

Jasper, D. (2004). A short introduction to hermeneutics. Louisville, KY: Westminster John Knox Press.

Jones, S. R., \& McEwen, M. K. (2000). A conceptual model of multiple dimensions of identity. Journal of College Student Development, 41(4), 405-414. Retrieved from EBSCOhost.

Juntunen, C. L., Barraclough, D. J., Broneck, C. L., Seibel, G. A., Winrow, S. A., \& Morin, P. M. (2001). American Indian perspectives on the career journey. Journal of Counseling Psychology, 48(3), 274-285. doi:10.1037/0022-0167.48.3.274

Kawulich, B.B. (2000, January 1). Influence of Skills and Education on Work Choices of Muscogee (Creek) Women. (ERIC Document Reproduction Service No. ED441963) Retrieved from ERIC database.

Kvale, S. (1987). Validity in the qualitative research interview. Methods, 1, 37-72.

Kvale, S., \& Brinkmann, S. (2009). InterViews: Learning the Craft of Qualitative Research Interviewing (2nd ed.). Thousand Oaks, CA: Sage.

Lin, R., LaCounte, D., \& Eder, J. (1988). A study of Native American students in a predominantly White college. Journal of American Indian Education, 27, 8-15. 
McCloskey, C., \& Mintz, L. (2005) A culturally oriented approach for career counseling with Native American women. In B.W. Walsh, (Ed.), Handbook of Career Counseling for Women (pp. 315-349). Mahwah, NJ: Lawrence Erlbaum Associates, Inc.

Mendelson, M. (2004). Aboriginal People in Canada's Labour Market: Work and Unemployment, Today and Tomorrow. Ottawa: The Caledon Institute of Social Policy.

Milligan, S., \& Bougie, E. (2009, Oct. 28). First Nations women and postsecondary education in Canada: Snapshots from the census. Retrieved from http:/www.statcan.gc.ca/pub/81004-x/2009004/article/11017-eng.htm

Packer, M. J. (1985). Hermeneutic inquiry in the study of human contact. American Psychologist, 40(10), 1081-1093. doi:10.1037/0003-066X.40.10.1081.

Parker, R. A., \& Aldwin C. M. (1994). Desiring careers but loving families: Period, cohort, and gender effects in career and family orientations. Job stress in a changing workforce: Investigating gender, diversity, and family issues. Washington: American Psychological Association: 23-38.

Patton, M. Q. (1990). Qualitative evaluation and research methods (2 ${ }^{\text {nd }}$ ed.). Newbury Park, CA: Sage.

Polkinghorne, D. E. (1991). Generalization and qualitative research: Issues of external validity. Paper presented at the American Educational Research Association Annual Meeting, Chicago.

Polkinghorne, D. E. (1984). Further extensions of methodological diversity for counseling psychology. Journal of Counseling Psychology, 31(4), 416-429. doi: 10.1037/00220167.31.4.416 
Reddy, M. A. (Ed.). (1993). Statistical record of native North Americans. Washington, DC: Gale Research.

Rudy, R. M., Popova, L., \& Linz, D. G. (2010). The context of current content analysis of gender roles: An introduction to a special issue. Sex Roles, 62(11-12), 705-720. doi:10.1007/s11199-010-9807-1

Schwandt, T. A. (2000). Three epistemological stances for qualitative inquiry. In N. K. Denzin \& Y. S. Lincoln (Eds.), Handbook of qualitative research (2nd ed., pp. 189-213). Thousand Oaks, CA: Sage.

Schwandt, T. A. (2007). The sage dictionary of qualitative inquiry ( $3^{\text {rd }}$ ed.). Thousand Oaks, CA: Sage.

Sue, D.W., \& Sue, D. (1999). Counseling the culturally different: theory and practice (3rd ed.). New York: J. Wiley \& Sons.

Thomason, T. C. (1999). Improving the recruitment and retention of Native American students in psychology. Cultural Diversity and Ethnic Minority Psychology, 5(4), 308-316. doi:10.1037/1099-9809.5.4.308

U.S. Bureau of Labor Statistics. (2011, March). BLS spotlight on statistics: Women at work. Retrieved from http://www.bls.gov/spotlight/2011/women/pdf/women_bls_spotlight.pdf

U.S. Department of Education. (1998). American Indians and Alaska Natives in postsecondary education. Washington, DC: U.S. Government Printing Office.

U.S. Department of Labor. (2007). Employment status of women and men in 2007. Retrieved from http://www.dol.gov/wb/factsheets/Qf-ESWM07.htm 
Weer, C. H., Greenhaus, J. H., Colakoglu, S., \& Foley, S. (2006). The role of maternal employment, role-altering strategies, and gender in college students' expectations of work-family conflict. Sex Roles, 55(7-8), 535-544. doi:10.1007/s11199-006-9107-y 


\section{APPENDIX A:}

\section{REVIEW OF LITERATURE}

This literature review will first discuss the current literature regarding work and family, specifically with respect to the work and family conflict. The topic will then turn to studies that have been done within the dominant United States and Canadian culture regarding the expectations that college students have about their future or current need to balance work and family issues. The review will then discuss general historical influences and cultural factors that influence indigenous women, with specific focus on Navajo and Cree women, as well as the few studies that have explored work and family balance with indigenous women. Finally, the current research around indigenous women college students will be discussed, as well as the need for additional investigation of indigenous college students' perspectives and expectations for college, work, and family.

\section{Work and Family}

Inquiry into the work and family interface has increased dramatically over the last 25

years (Weer, Greenhaus, Colakoglu, \& Foley, (2006); Alfred P. Sloan Foundation [Sloan Foundation], 2008). As the labor force continues to become more varied in its demographical make-up, and as more women enter the work force (over 59.3\% of women in 2007 versus 18.8\% in 1900 (US Department of Labor)), understanding the nature of the pressures and decisions that individuals face regarding work and family becomes increasingly more important. This is especially true given that women are working longer hours than in previous decades and at times combine work with parenting (Schnittker, 2007). The Sloan Foundation (2008) has found that “working mothers lose approximately one night’s worth of sleep a week, due to the combined demands of work and family; husbands whose wives work 40 or more hours a week experience 
poorer health than do husband whose wives work shorter hours; [and] the U.S. economy incurs a significant loss of human capital in that many highly educated, middle-class mothers leave the work force, because they cannot get career-continuous, part-time arrangements” (Sloan Foundation, para. 3).

Literature on the impact of the work-family conflict on women and men is mixed. In their review of the literature, Emslie and Hunt (2009) found some studies in which women reported more conflict between paid and family work. Other studies reported that men and women experience equal amounts of conflict but differ in their perceptions of paid employment, use of flexible time, and ability to separate work and home stress, with women more inclined to worry about work at home (c.f. Emslie \& Hunt, 2009). This stress was particularly great for women who identified themselves as being dedicated to their families (Emslie \& Hunt, 2009). Qualitatively speaking, the challenge for many working mothers is highlighted when one considers the second shift that women with families tend to work - that of housework. Research “consistently shows that women do the bulk of the housework, averaging about $70 \%$ of household tasks” (Johnson \& Johnson, 2008, p. 488). Stark as these numbers may be initially appear, without an understanding of the meaning individuals give to this apparent disparity it is difficult to make sense of individuals’ felt reality.

The increase in the amount of research on the work-family relationship has been accompanied by a growing effort to understand the benefits of working and the meaning that individuals make of their occupational roles (Parker \& Aldwin, 1994). Since 1969, women have become increasingly more likely to endorse career as a salient and satisfying role (Parker \& Aldwin, 1994). However, the majority of women continued to cite family as the area in which they expect to receive the greatest amount of life satisfaction (Parker \& Aldwin, 1994). Parker 
and Aldwin stated that the greatest career-family stress was found when low value was placed on career and high value on family and that less stress was anticipated when individuals placed high value on career (1994). While working can increase the stress felt by women, Schnittker (2007) reported that benefits of working seem to arise as a function of value placed on career and family. Schnittker stated that employment provides greater overall satisfaction and health benefits for women as the value placed on careers and education increases (2007). However, health benefits decline when working is combined with the care of a young child (Schnittker, 2007). Thus work-life balance (the degree to which an individual is equally involved in and satisfied with their work and family roles; Gregory \& Milner, 2009) becomes a pertinent topic to address with those who are preparing to enter the workforce.

\section{College Students’ Expectations}

With the many aspects of balancing ${ }^{1}$ work and family being well documented in research and in popular culture (c.f. Fouad \& Tinsley, 1997), the decision-making processes and expectations of college students who are preparing to enter both the work-force and family life deserve attention. One study of college upperclassmen (Friedman \& Weissbrod, 2005) found that there seemed to be no difference between men and women's commitment to both work and family. However, women expected to have to compromise between work and family, with a significant negative correlation between work and family commitment (e.g. increased work commitment would need to lead to a decreased family commitment). Friedman and Weissbrod (2005) reported that women were more likely than men to have already decided whether they plan on marriage, parenthood, and family roles, and were more likely to have high commitment to family and low commitment to career.

\footnotetext{
${ }^{1}$ Some authors challenge the idea of using the term "balance" when discussing the interface between work and family. See Sabelis, Nencel, Knights, \& Odih (2008); Gergory \& Milner, (2009)
} 
This being said, the degree to which female college students anticipate work-family conflict is unclear. Hallett and Gilbert (1997) found that many female college students operate under the assumption that having both a career and a family is possible instead of needing to choose between the two competing domains. This is distinct from previous generations' expectation that women would need to choose between the two domains (Hallett \& Gilbert, 1997). They also found that neither those who anticipate a role-sharing marriage nor those who anticipate a more conventionally structured dual-career marriage seem to expect much conflict in balancing the demands on their time (except in finding child care). Livingston, Burley, \& Springer (1996) found that high individual endorsement of characteristics that are traditionally seen as feminine seems to be correlated with low anticipation of conflict for both genders. Interestingly, for women who endorsed a low level of characteristics that are traditionally seen as feminine, a low commitment to work was correlated with higher anticipated work-family conflict.

Individual's experiences with maternal employment in their families of origin also seem to impact the level of anticipated family-work conflict (Barnett, Gareis, James, \& Steele, 2003). However, the literature on how maternal employment affects male and female college students' anticipation of work-family conflict is inconclusive. Barnett, et al. (2003) found that college seniors whose mothers worked were not as concerned about future conflict between careers and romantic relationships as those whose mothers did not work (regardless of the gender of the student or minority status). Other studies did differentiate based on gender. For example, Weer et al. (2006) found that those male students whose mothers were highly employed expected to have more work-family conflict than their female counterparts; female students tended to expect moderate to high work-family conflict regardless of maternal employment. However, for both 
genders, those who expected to have work-family conflict were more likely anticipate a delay in marriage (c.f. Hallett \& Gilbert, 1997) with fewer children (or no children at all) when compared to those who did not anticipate much work-family conflict (Weer et al., 2006). It is interesting to note that the anticipation of work-family conflict did not alter students' expectations for their future careers (Weer et al, 2006).

Research findings on the degree to which students expect work-family conflict vary, yet the majority of findings contribute to a hopeful outlook for the merging of work and family roles by college students. Cultural factors influence how students anticipate filling work and family roles. However, culture becomes an important factor to consider. For example, in a study conducted with students at an Israeli University, women anticipated higher levels of work-family conflict and reported feeling less efficacious in their ability to handle the conflict than their male counterparts (Cinamon, 2006). The study of this phenomenon among various cultural and ethnic groups becomes important in gaining a richer understanding of the diverse student body in today's colleges and universities. One group with a growing population on college campuses is indigenous students, specifically Native American and First Nations (Milligan \& Bougie, 2009, Freeman \& Fox, 2005). While some of the articles on work-family conflict have included Native American or First Nations women, very few have focused specifically on the unique historical, cultural, and familial factors that emerge from these indigenous groups.

\section{Historical Influences on Indigenous Women}

There are over 500 federally recognized Native American tribes (Juntunen et al., 2001) and more than 600 First Nations bands (Indian and Northern Affairs Canada, 2010), each with distinct languages, customs, traditions, and values. It would be beyond the scope of this paper to outline each of these traditions, but there are shared historical factors and experiences that 
provide an important background. These factors include a history of discrimination, colonization and oppression, intergenerational trauma, residential/boarding schools, strong family ties and commitment, attachment to homeland, the importance of the community, and a demand from the educational system to be culturally fluent in both their culture and the culture of the Western work force and academia (Juntunen et al., 2001; Shepard, O'Neill, \& Guenette, 2006). These experiences are broad, and can be manifest in differing ways depending on the tribe, clan, or nationality. For example, the Indian Act of Canada of 1876 had devastating effects on First Nations women. The Act took away previously established women's rights in their bands (i.e. voting, holding public office, and property rights), stripped them of their communal authority, and diminished the power of women in their families by instituting a European patriarchal system (Bourassa \& Hampton, 2004).

These experiences are a sampling of the unique history and current challenges faced by this population. Additional challenges include the prevalence of poverty (Reutter, Neufeld, \& Harrison, 2000), health concerns, single-parent households, racism, alcohol and drug use, and spiritual and traditional concerns to name a few (McCloskey \& Mintz, 2005). It is noteworthy that single parents are more likely than their married counterparts to experience work-family conflict, and Native American women are more likely than White women to be the head of a single-parent household (Barnett et al., 2003). Each of the aforementioned factors greatly impacts indigenous women, their families, and their communities. For many indigenous women, historical realities that impact coping and adaptive strategies can lead to increased stress and difficulty in efforts to manage multiple family, work, and community roles (Cvetkovich, Baumgardner, \& Trimble, 1984). 


\section{Indigenous Women's Work and Family}

Even with the increase in research on the relationship between work and family relatively little research has focused on indigenous women's view of work and family. What has been written thus far may be helpful in working with indigenous populations. Women are often responsible for a majority of the home-related work (Kawulich, 2000). In indigenous families, women play a strong role, and the extended family (which often extends through the second cousin) shares responsibility for the education and raising of children (Sue \& Sue, 1999). For indigenous women, the demands of home are only a portion the work they perform. For example, participants in a study by Kawulich (2000) described work in four overlapping domains: home work (related to agricultural/rural upbringing, taught by female family members), public work (working outside of the home for pay), community/volunteer work (dancing, teaching language, and other projects where they could preserve the culture), and cultural/home jobs (crafts such as beading or metal work).

The view of work put forward by Kawulich $(1998,2000)$ expands upon Western culture’s tradition view of gainful employment "work," which may be too constrictive in the traditional idea of a work-family balance, and creates room for a richer description of life work. Work has been defined as "a way to survive, a way to better their circumstances and those of their families” (Kawulich, 1998, p. 150). This expanded view is congruent with what was found by Juntunen et al. (2001) in interviews about the meaning of career. Many of the participants defined career as a life-long endeavor, with one stating,

[Career is] what you do with your life ... if you can live a good life, you'll have a good career... [referring to a family that cares for their elders, even though they have no money 
or jobs] ... this is a career because they are continuing on the tribes ... how is your existence going to continue for the future generations? (p. 278)

Individuals who come into contact with another culture vary in the degree to which they adopt the behavior, norms, and values of the second culture (Bichsel \& Mallinckrodt, 2001). As indigenous women enter into the workforce and college they face the challenge of integrating another culture while maintaining a connection with their own. A few studies have explored indigenous people’s experience of work and family life (Kawulich, 2000; Napholz, 2000). Napholz (2000) explored the experience of 8 Native American women who were in the midst of balancing their roles as mothers, wives, and employees. The women reported that the balancing of multiple roles was manifest in an attempt to "integrate and balance traditional and contemporary feminine strengths in a positive, culturally consistent manner” (p. 255).

Napholz (2000) reported that urban Native American working women tended to be more isolated from the support structure of their native culture and to experience an increased amount of bicultural stress and psychosocial problems. Participants addressed traditional sex role expectation conflicts, family guilt, and spiritual concerns and described feeling their stress lessened as they reconnected to their native culture in meaningful ways. For the women, culture became a source of strength both in family life and in managing work roles. Given the conflict regarding sex role expectation for indigenous women in the workforce, and the importance of the connection to the culture, the question arises as to what indigenous women who are just beginning their education and career journey experience.

\section{Indigenous Female College Students}

An increased connection with traditional culture and flexibility within the dominant culture can benefit indigenous women in the workplace (Napholz, 2000). In addition, a bicultural 
identify and connection with Native culture may be psychologically, academically, and socially beneficial for indigenous college students (Juntunen et al., 2001; Jackson \& Smith, 2001). Education is seen as something that is desirable and helpful for many indigenous students, especially in augmenting the student's ability to find future employment (Kawulich, 2000). However, some students experience a paradoxical cultural pressure to both gain an education and maintain their cultural identity (Jackson, Smith \& Hill, 2003) and may be met with both positive and negative reactions from peers within the band or tribe (Kawulich, 2000). This pressure, combined with the felt requirement to walk in "two worlds," may contribute to the poor academic persistence rate among capable indigenous college students (Juntunen et al., 2001; Jackson, Smith \& Hill, 2003). 


\section{APPENDIX B:}

\section{ADDITIONAL SUPPORT FOR THEMES}

The following sections contain participant quotes that further support and explain the themes identified in participant interviews. Selected quotes may be additional quotes or expanded sections of quotes previously cited in the body of the text.

\section{Honoring Indigenous Culture and Community}

This theme reflected participants' commitment to their indigenous culture and to the community from which they came. Additional quotes that support this theme follow:

Participant 16: It gets, well, being a Cree person and a Cree woman, you are supposed to kind of know who you are, and your culture and all this - you know? ...I hate to say that when someone is Cree like me and they are a woman and they don't really don't know about tradition and or about powwow or anything, then I would think, “they aren’t really an Indian,” like serious. I would think that's part of it. That's really an important part. I look down at people like that. I am not going to lie, because you think... that you really aren’t native. Like, do you really know some Cree, or do you know what a powwow is or whatever? That's the pressure. You need to know your culture and who you are.

Participant 20: I used to dance and sing and everything and now I don’t do anything. And so I am going to start getting back into that. Because it is like, I don’t know, just like when I came here, I lost myself when I came here. Like, I am not me anymore - the way I would be when I was at home - and I do not like the way it feels. It feels like I have no culture just being in such a city atmosphere. We were in a city at my high school but we had native things every day to do. We would even smudge in the morning. Every 
morning there would be smudge by the door when we came in and it was just awesome. There are elders all the time kicking around somewhere and you just have to find them. So it's just so different when you come here. You have nothing and nobody and you're just coming in and sitting here. It is an average student center and it is a little comforting. But it's like nothing compared to my old school...my old school was just totally cultural based and I succeed so well there.

Participant 13: Well there's like from our band there’s . He is our counselor and so he'll come up to the aboriginal center and we'll see him and he'll be like "hi." He will greet us or whatever. So it’s good to see involvement from the band helping at school so it doesn't seem just like "here's the tuition, here's some money for them," and they go off on their own. It's good to see like that they are getting involved and actually keeping tabs on us.

Participant 6: ...there's people that are not related to me. They're supporting me and they are happy to see a person like me going to school...my teachers that aren’t here, they ask me what I am doing. I tell them I am going back to school. They say “Good for you.” I know that they are excited that I am going back to school.

Cultural preservation. One example of honoring indigenous culture and community was seen in the participants' desire to pass on their tradition, language, and heritage on to their children. The following quotes illustrate this theme:

Participant 4: I want to pass the whole package. I mean my grandparents and my parents they, they taught me everything. They taught me the whole thing, the if's, the no's and 
yes's and the what things not to do, what's this, and what to expect and what you need to do...like all the culture in the valley, they taught me. I actually carry it now. There are times I forget but it comes back to me later on. So, I want the whole thing, the stories the taboos, everything. I want my kids to know all of that stuff...We want our kids to know that, to know the whole tradition, to know the language and to know everything, the stories our grandparents have told us, everything, we want our kids to know that, to know that, that they know who they are, what tribe they came from, and not only that, to teach their children and their grandchildren.

Participant 11: I really do love my tradition and way, the heritage I come from. At the same time it is hard for me to understand. I am barely learning all of the traditions right now because I feel in a way it's my responsibility to carry on that heritage. I think about whether I can try to carry it.... The main reason that I want to stay in this area and have [my daughter] go to school in Zuni is because I'm trying to let her learn the language and the culture because at this time in her life is the time that she can really, I guess, be like a sponge and learn all of the things that I never learned at that time. Because I really, I really care about not losing the language of the Zuni people and I believe that there's so much we can give them to start - that's the best time. So, that's why I want to stay - so she can learn all that and hopefully teach me something one of these days.

Service to Indigenous community. Another example of honoring indigenous culture and community was through being of service to the indigenous community. This was illustrated in comments that reflected a commitment to (a) serving as a role model and (b) serving through career choice. 
Serving as a role model. Participants discussed serving their indigenous community through being a role model to others, including indigenous youth, family members, and women who desired to go back to school after having raised a family.

Participant 14: My getting an education would be better because I would be a role model to my children. I would show that there are some people out there that choose not to educate themselves and some of them have chosen a bad route. And having an education does give you a positive spin on life rather that all this negativity and stuff like that. And coming to school, being able to meet new people, experience new things - that is how I felt when my mother went to school. She was meeting new people and she was learning new things and every time she would bring her books home they looked like little kids books, and I am really like you guys going to read this? And maybe that's how like I want my children - my future children I guess - to see when I bring books home. They are reading it and they want to learn more, more, more.

Participant 4: I think my tradition and values, my grandparents and my family and what their values and culture are...I think those things pretty much motivate me to go to school. ... Not only that, there's Navajo children that are out there and they are neglected and they are out there running around, and when they see a young Native American go to school, you know they look up to you and they are like, "oh I can do that, too. I can be successful like that too.” They can go ahead to change their life style and turn their life around to go in the right direction.

Interviewer: There is a power in that example. 
Participant 4: Yeah, there is a lot of power, and there are a lot of kids who look up to you and they will say “OK.” Like right now there are probably young teenagers that are running around that don’t go to school, you know? ... They ask you, "What do you do?” Tell them to go to school and have a career. And they will think about that, and they will think, “Well, that's what I want,” and that's when they change their lifestyle to what they want it to be instead of living in their negative ways. They go to the positive ways. Wow, I didn’t think that I could do all that.

Serving through career. Participants also discussed serving their communities through using their education to work on their reserve or reservation and improve the condition of their indigenous communities.

Participant 11: I just thought to myself, you know, that if people could understand that they could be so much more than this - drinking and doing drugs - then there is no limit to what you can do. That's what mainly keeps me from heading down the path of where I see all my relatives. Because there is a little bit of a problem with alcoholism. That's another group of people I want to work with. It's just sad to see a community crumbling because of alcoholism, drugs, teen pregnancy, and I kind of have a sense that I have that responsibility to (laughs) - going back to the question - my daughter and to myself. I want to look back, I don’t know how many years - before when I am old - [and know] that what I accomplish are really good things - that I want to - for the nation.... Participant 2: When I first signed up to form my major, I put my major as associate in psychology... I had an idea that I wanted to become a therapist or psychologist kind of person and then use that back on the reservation. ...the way I grew up, there's not a lot of 
that, actually none of that, on the reservation for people to know what psychological problems they might have, or why there are all of these problems out there.

Participant 20: I just wanted to get my education so I could actually do something about what I see like at home. Make a difference at home. Why go somewhere else and try to make a difference where you don’t even know anybody? It just means a lot more when you grew up with people and you see them - or you babysat these people and all of a sudden they are going through like the US justice system and stuff. It is just like a "Man! Buddy, I want to help you so bad.” And so it will just be different. You'll feel really cool... Not only [make a difference in] their lives but in the community. Because when somebody gets in trouble it is such a small community everybody knows and it makes people feel better to see one of their own, one of their own youths, one of their own people, making a difference in their people's lives. It's going to be a lot different than to have a stranger, come along, “yeah I am going to represent you your son.” Interviewer: So where do you want to go after?

Participant 20: Home. Yeah I don’t care where I work or what I do specifically as long as it is in ... the justice system or with criminal law or whatever. I don't care what it is as long as I am at home and working... There is nothing like home. That's what I always tell everyone, “Oh I can’t wait to be done.” "Why where are you going to be after?” Home.

\section{Living in Two Worlds}

Participant interviews also described a need to be fluent in both their indigenous culture and in the dominant culture that surrounded them. Several quotes illustrate this theme: 
Participant 6: It [boarding school] kind of taught me two different worlds and, umm, and my grandpa always taught me to never forget your culture.

Participant 11: I never really got to learn the Zuni language....and I guess being a Zuni woman, it’s hard, because my grandmas and all my family members will tell me, “you know, you need to go help us cook and do all these traditional things” and I try to go but it's hard because everybody is speaking Zuni and I hardly know what they are talking about. But my role probably is mainly a nurturer, being a mother, but also at the same time with all these other outside things like going to school, it's become more contemporary towards the modern life because we have basically two things to do - our traditional ways and the ways of the world around us.

Participant 2: I spent more time with my grandma, and being with my grandma, she taught me a lot about my spiritual side. At the same time, because I was living in the city when I was younger, I spent a lot of my time being modern too. So I'm kind of modern traditional in a sense. I still go to sweats, and I stay in touch with my spiritual side, just not as much as I used to when I was younger. Being in the city I kind of find it a little harder to get around to, compared to a small town.

Interviewer: As you... as you came to school was there anything that was difficult for you?

Participant 13: Yes, trying to find my classes and getting used to the city life and being like alone... adjusting to being alone.... I would turn on the TV and just turn it up so I 
wouldn't be alone, so there would be noise in the house going on so...it feels like a home. So now I'm getting better at it. I used to go home every weekend because I didn't want to be alone, but now I'm getting better at it. So now I'm kind of like, “I'll go home in two weeks time (laughter) and I'll go see them then." So it's good. And I got used to living alone, so when I go home I'm like, “ahhh...you're kind of in my stuff.” It wasn't until I got use to alone and living on my own.

Interviewer: So before it was kind of like, "what's mine is yours, and what's yours is mine,” and now, “it’s mine?”

Participants 13: “That’s mine! What are you doing?” I’m like, “that's mine!”

Participant 6: ...now it's different. They have utilities. They have phones. They have running water being installed. It's different now. So a lot of the reservations are changing more into the white world than their culture. A lot of them are speaking English and they are being raised by English so sometime it is frustrating but I can’t really do anything about it....

Interviewer: ...it sounds like it's something that you aren't exactly completely excited to see change?

Participant 6: It's good that they are doing that but you know it would be really good, too, if they keep their culture and keep their language. You know? Just never forget your language. You know? Never forget your culture. Never forget your traditions, your spirituality. Keep it. You can learn and you can learn as much as anything in the world that you know what the white people can give you. Learn as much as you can but never forget your culture, your language, whatever you have. 
Academic persistence. One way that the participants described the interaction with the dominant culture was through their desire to finish school and to encourage others to finish: Interviewer: What do you think is the most important thing for you to do here right now? Participant 8: The most important thing for me to do right now? To finish college... try to finish college...

Participant 9: Stay in school. That's pretty much what I tell these guys here, the students. Don't worry about the guys, don’t worry about the girls. That will come later; just do your schoolwork first. Some of them, the older students, some of them already have families and they find it very hard to deal with both. I encourage them by saying, "I didn’t do it but you are doing it, and that’s a good thing.” You know? “Just keep on doing what you are doing. You got to be doing something right because you are here and your family is still surviving,” and so forth. I try and encourage them that way...to stay in school. It will be worth it in the long run, and I think at one point that's what people had to tell me - it will be worth it in the long run - so I keep telling myself that especially the days when I get really discouraged and keep saying it will be worth it will be alright. It will go by fast.

Spiritual tension. Participants discussed tension between the spiritual tradition of their indigenous culture and the religious traditions of the dominant culture. Resolution of this tension was portrayed in various ways:

Interviewer: How does knowing who you are influence what you do now?

Participant 16: It’s kind of hard. I am out here by myself, most of the ceremonies I like to go to are at home, you know what I mean? There isn't a lot of that in the city. There is 
only a couple of sweats. Balancing the spiritual part - the Cree - and the education is really hard because there is no room for spirituality in education. There's nothing, so they don't mesh together. Combining those two is hard. I try to smudge every morning or pray at least and the other thing I like to do is go to ceremonies and stuff but you can't just get up and go in the city, and you can't just go [home] because you have school to go to and some people have work to go to. And they don't have the ability to do that.

Interviewer: That must be tough. It seems like there's that part of your life that you almost have to have it on the side.

Participant 16: Yeah it is, it's either one or the other, and education is a lot more important, I think, to me than spirituality. I can, I will go, I would try and go home and go to a sweat go to something else, a big ceremony or a powwow even, but getting there is hard.

Participant 9: I am alright. They fit together. My grandparents were Protestants and my mother was Catholic and we grew up Catholic. But on one of my grandfathers' side they were very traditional, and so one of the points I think they made to us when we were very young was that regardless of which way we went or how we chose to go we had to love each other and respect each other's ways. And one of the important things is at least learn about each other's ways and never condemn each other's ways and to remember that there was one creator whichever we called him...so... as I am older now I can go to that church and I am alright with that church. I know who I am praying to. I go to this church I am alright with this church because I know what I am doing there. 
Participant 4: I go to church sometimes and sometimes I am traditional, I am half and half. When people criticize me because I am more traditional, what I do, what I practice, when they criticize my tradition it kind of gets me angry sometimes because they don't realize that it's the same thing, I want to teach my kids it's the same thing, you know? It is ok to go both ways. I mean right now I am actually really traditional with my family, I am really, really traditional. But I do go to church, too. It doesn’t bother me because I was raised traditionally. My parents don’t get after me because I go to church sometimes because I tell my parents it's the same thing, it’s just done differently.

Participant 17: But I’ve been kind of scared because religion is something I'm not very fond of because of Christianity. I took some native studies courses back where I come from, and they just really broke my heart, all those classes that I took. So ever since then I’ve just been really, really iffy about all the religions. I'm not atheist. I do believe that there's a greater power out there. I just...getting in touch with the right power is my problem.

\section{Influence of Women's Rights movements}

A theme reflecting the influence of women's rights movements was portrayed through (a) shifting roles of women and (b) advocacy.

Shifting views of the role of women. Participants discussed generational shifts in female roles both in the family and in the community.

Participant 16: I am the oldest, so I am the first one to come to University. Even out of my mom and grandparents. My Kokum, she didn’t even have education. She only knew how to spell her name. She didn’t even speak English. She spoke nothing but Cree. So 
it's a big thing. Then my mom, like she went to school she finished high school...and then I am the first one to be in university and the first one to move out of the band and come live by myself.

Participant 2: ... as far as the way my husband's family, they're more traditional. They're OK with my generation going to school and stuff, but before that generation, my aunts and uncles, they don't believe that they should go to school. My mom's generation, on my in-law's side, most of my in-laws, my husband’s aunties, are like mostly all house wives. [Her] husband goes to work and she stays home.

Participant 2: But at the same time I want to teach [my husband]... my kind of way. Because my kind of way - I grew up with my dad helping my mom all the time. He would be there making the bread, which traditionally they're not supposed to. But my cousin and brother, they all know how to make dough, they make bread. And for him, all his brothers are always in there with their feet up and their wives are in the kitchen... not even over there helping or anything... When he came with me he was just doing that. I said, “Get up! Come on, help me.” And he still doesn’t like it.

Participant 5:... if you are a mother, just [the] husband should be more supportive of what we do and what decisions are made between both of them, and for your kids....

Advocacy. Education within the dominant culture was discussed as way to gain a stronger voice, a sense of empowerment, and credibility. The participants spoke up for themselves, other women, and for their indigenous community in response to sexism and racism. 
Participant 15: ...I thought by coming here and doing it kind of on my own, other people will follow. You can only hope that they would. I think the only other way to make a big change, politically or administratively in politics through my reserve is by coming here and grabbing my degree or another two degrees and going back and saying, 'Look! I am not just a bantering idiot at membership meeting; you have to listen to me.'

Interviewer: What obstacles do you face?

Participant 14: Well, for me it's, it's being able to try to beat the men! Because at times you always get those stereotypes that women are weak and they hardly do anything. And then you have the race, where race is a big issue. And at times I try to prove myself - that I can work no matter my skin color. I have a working ability that is at the same level as any other person. And it’s, at times it seem like, “okay you guys are putting me down I can't do this no more.” But I've got to be able to show them that we, as a whole, women can work, Aboriginal women can work. ... most of the Aboriginal women were in the teaching none of them were in the higher jobs where they were managers and stuff like that. Sometimes, I feel like I want to change that. But then again, I can’t because sometimes it becomes difficult. You have to face a lot of obstacles and you have to try to get yourself to the top. But at times, you stop at the bottom and you think, and you turn around.

Participant 4: I know as a Navajo you need to know your culture and know who you are, because later on there's going to be - you will meet people down the road who will ask who are you and "what kind of tribe are you" and that's when you come in showing your 
pride and being proud of yourself and saying, "I am Native American and this is what my culture is and this is where I am from.” And to teach other non-Native Americans, because they think that we are just out there, running around without shirts and running around with those little things they see on movies. This is where we come in to teach them that we are modern people, too. We do things, we have this, we have electricity, we go to work, and we do all that stuff and to teach them some of our culture.... There are some people out there that don't have that. There are people out there that have no water or electricity; they still live in hogans. Informing them gives them the knowledge to not to judge how they live or how they look.

Participant 16: I am proud of who I am. I am proud of being an Aboriginal person. I am proud of where our people are. But at the same time, I am not satisfied with were we are. I think we can get somewhere else, like we can get closer to equality because we are not even at an equal level at all. Were just slowly, slowly climbing like the stairs. ...Look at it like social stratification. No matter how successful we are it, there is always some way we are always at that level, and I think if we try and be more brave and more bold and if we get our education and just don't give up and don't be scared of being put down or for somebody to say we are Aboriginal... ...how different is running for politics then it is competing to rent a house or competing for a job. You're always going to get racism; you are always going to get turned down. Being Aboriginal people you should expect that by now and not be scared to be let down. You should expect it and if you don't, then be surprised. Why be scared to get put down or to get told, “You know, I don’t think you are going to make it,” and it’s like, “well, let’s just find out.” Why not, you know? I don’t 
know. I am proud to be an Aboriginal person and I think that we have what it takes to make it in the world. We just have to keep trying. We obviously haven't found the right way yet but I think eventually we will somehow.

Participant 20: My mom said, “You can’t do anything - you can’t change what is going on in the world - if you quit. And nobody is going to have any reason to listen to you. You are just going to be another voice.” I would be an average person just going somewhere with no education they wouldn’t usually take me seriously.... So I just stayed.

\section{Pursuing Individual Fulfillment and Goals}

The theme of pursuing individual fulfillment and goals addressed the participants' decisions to gain an education and pursue careers for personal improvement and fulfillment; often personal fulfillment was linked to the betterment of the family and the community.

Participant 17: It's like the dream come true. You know being a little kid and always driving by the university, I always wondered what it would be like to actually be a university student. And now that I'm here, and I see all these other high school students coming here to check it out, it's like, it makes me feel a sense of accomplishment that I actually did something great with... what I'm going to be. Interviewer: ... as you look into the future, what concerns do you have? Participant 17: Just about getting pregnant. I really hope I don’t. I don’t know what I would do if I ever became pregnant. Because, although there is that support there, I don't want to have to feel tied down... like I said. I know I'm being kind of selfish, kind of 
greedy and selfish with myself. Everyone has their own right to their own greed and their own selfishness. So, might as well live mine up.

Participant 20: Right now I just think...I have to get to know myself now. I am trying to understand myself more and get myself on the right path before I try to share it with somebody else. I don't need to get all confused with somebody else in there, and just be like, “uh, get away from me I am trying to reach my goals here!”

Participant 4: It makes me feel good to see that my cousins are, you know ,they are willing to better themselves and to get a career instead of a job, you know there is a difference between a job and career.... I motivated my mom because she hasn't been at school for awhile, and she is really excited. I guess I motivated her to attend - to keep going to school, because she wants to get a career and not just a job that she will stay on for awhile.

Interviewer: How do you see the difference between a career and job?

Participant 4: A career is something that you love, something that you have passion about, something that you were interested at the beginning, and you say this is what you wanted to do. You have passion about it; you love doing it. A job is just a job. You just go to any job. You get a job like at Wal-Mart. That is just a job. You get paid for it but you don’t love it, you don’t like what you do. But a career is something you go to school for and you like it and you love it and you enjoy going everyday to work. 


\section{Importance and Influence of Family}

The importance and influence of family (broadly defined by participants as blood relatives, adopted relatives, and family friends) was a major theme throughout the interviews. This theme was reflected in (a) family support and (b) family expectations and roles.

Family Support. Family was identified as the most influential support system in making a decision to pursue an education and in participants' experience as students.

Participant 20: I would just say it is going to be really hard. And you're going to get marks that you are not happy with that you are not used to and everything is just going to be moving so fast and you are going to feel so alone and just keep in touch with your family and visit regularly. And make phone calls and just like make sure you have support other than at school. And make sure you have support at home all the time that you have somebody you can phone and somebody that you can talk to and just be prepared to grow up.

Interviewer: What, what's your support like what's gotten you through other than your goals?

Participant 20: My family. My family. Like big time. When I was like feeling lonely or when I was going through a hard time my mom would come down all the time and then as long as I had her support and I had her there talking there talking to me. I would cry to her and tell her, “I can’t do this I can’t do this anymore. I want to go home...I miss family, I miss you, and I miss our house, I miss my dog, I miss like, everything.” 
Participant 9: I think it is important to have your family and it is important to know that your family supports you. For a long time I was thinking that I was doing this on my own and I was the only one missing them and it took me a while that they missed me too and they loved me and I know that I have their support. Because they never told me, or they never...you know the way I looked at it was, “oh, grandmas gone, and so it’s ok,” you know and I missed them talking to me or telling me "you are doing a good thing grandma.” ... now I see how much they miss me and then that encourages me to keep on doing what I am doing so that I can hurry up and go home, and that is a big thing to feel that support from my family

Family expectations and roles. In addition to the support that family provided, participants addressed family influence regarding (a) expectations for career/education, (b) gender-based roles and expectations, and (c) balancing roles and expectations for family, school, and career.

Expectations for career and education. Family expectations for career and education were influential in participants' education and career paths. This is illustrated by the following quotes:

Interviewer: How do they [your family] feel about you going to college?

Participant 3: At first they didn't like it. They thought I should just work and provide for my kids. But after a while they began to realize, maybe she is doing it the right way. And now they don't say anything to me, not anymore. They don't bother me. They just more help me more even more now. 
Participant 13: I guess my parents, mostly my mom because...education was important to them and so they saw people that lived on the reserve who didn't really have an education and didn’t really have like I guess, a way of supporting themselves. And so umm...she wanted us to have an education and then get a good job. So we would be like financially stable for our kids.

Participant 3: I had graduated and I wasn't sure what I was supposed to do. My parents told me that I would have to go to work that is all I knew I didn't know where or how or anything like that. I know a friend of mine said they were going to look for a job. So I said okay I am going to go. So I thought like a theater or something kind of cool kind of job but they were into housekeeping and I didn’t know. Ha. But we all got hired that day and we all started working that day and I said this is not for me, and I remember in high school they had the career stuff and all that and they said to go to college. But my parents never told me to go to college or anything like that. So I thought oh maybe I'll just try it. So I remember I had got a letter from [my college], just went by that and I started going to college but I wasn't sure what I wanted to do as a degrees so I picked business... Interviewer: How do they [your family] feel about you going to college? Participant 3: At first they didn’t like it. They thought I should just work and provide for my kids. But after a while they began to realize, maybe she is doing it the right way. And now they don’t say anything to me, not anymore. They don't bother me. They just more help me more even more now. 
Participant 2: Once they heard that we had a baby it just totally changed. You know, you have to provide for that baby. School is ok, but you got to make that money for them. Now your school is kind of pushed back kind of attitude. But before we had the kid we were going to both go to school and we were happy about it. Up to that point we found out we were going to have a baby. And my side of the family, I really, really, what would you say, failed their expectations. They were really upset that I got pregnant... my parents were really shocked... my dad actually cried. "I don’t want that for you, I want you to go to school, I don't want you to have a baby at a young age. We told you no, no boys, no boys, but that's what you wanted.” But they were more accepting, but really disappointed, and it just made me hurt, too, because I felt like a failure. That was one reason that kind of pushed me. I'm not going to fail. I'm not going to disappoint you guys. I have a baby, but I'm still going to go to school. So that phase passed over right after they saw her. They were like, “oh, forget it. We love you.”

Participant 10: Actually I didn’t really want to go to school, but, right now I just want to and I'm trying to finish. But what I'm hoping is that I'll get like an education, a good job, later on... Yeah.

Interviewer: What was it that changed for you?

Participant 10: I didn’t want to go to school. When I was in high school I didn’t want to go to college I just wanted to get a job right after but when I met my boyfriend, his mom... his mom made me go to school. 
Participant 2: I always tell myself, white man... there’s people that just work for the money and want to succeed and have the best things in life. And then there's the people that want to have a job that still have time with their family. I don't want to be one of those people that's just constantly just working, working, working, and just forgetting about the important people in their lives. So I'm kind of trying to find some job where I can have like an eight to five kind of job and be there for my kids.

Gender-based roles and expectations. Participants discussed gender-based roles as well as variation in the gender expectations within the same family and across generations.

Participant 7: And I would rather have myself starve than my child. I am still not ready for that. I just freak out when people talk about it - like family. Because I got married it seems like they have this pressure on me like I am going to have kids or something. It is kind of hard, but I think they kind of understand now that I have explained...to them...how hard it is. I am not ready for that...they don't bug me about that any more after I made clear to them that I am not.

Interviewer: ...from the Navajo tradition are there any expectations on you as a woman as you go forward?

Participant 4: Actually, yes.... You can do whatever you want just know that if you want a career and go to school that's good, that's ok, but the main thing is to be there once you have kids, to provide for your children, to be there to show love to your kids and to teach them the culture and the values and also to go to school and accomplish what you wanted to do, and being there for your husband or your spouse and to provide that support for them. I think those are pretty much the things I learned from my grandparents and my 
mom. And that our expectation is to provide nourishment to our kids and then to have two different roles as a mother and to continue our careers in what we want to do.

Participant 2: But, he just keeps telling me, “Go ahead and just keep going to school when I'll just be here to, you know, pay the bills. Just go ahead and do your thing...just as long as you take care of the kids.” You know just our roles and stuff?

Interviewer: Do you feel like you would have done it differently?

Participant 9: Listen? I would have. I had a father that was so over bearing and so strong and I married to get out of the house, and because like in our way we don't leave the house until you are married and they don't push you to get married. They want you to be home all the time, and in our tradition the women wait on the man hand and foot so it was better for me, according to him, to stay at home because then he had anything and everything he wanted as far as home cooked meals and stuff like that. And because my mom worked too, because they only finished high school but they both worked and being the eldest of the kids I had a lot of responsibilities, so when my younger brothers and sisters came around I was ready to get out of the house.

Participant 17: But with family, I'm not even sure because I don't plan on having much. I plan on having one or two kids when I'm done with university, if that, so I don't really see myself having a family. Having already taking care of a couple of little babies, watching them grow up to be the age they are now - they're nine and ten now - so I've already accomplished that and I don't think I want that. It would be nice to have my own 
kids but lots of my friends already have kids. Seeing them struggling with theirs makes me not want to have kids.

Balancing roles and expectations for family, school, and career. The tension between the multiple roles that participants fill was reflected in a desire to give time and support to family while focusing on school and work. The expectations of immediate and extended family were influential in participants’ experiences.

Participant 2: You know what? Come to think of it right now, I actually fill both roles my own role, where I don't have to stay home and do those, where I can still go to school and strive towards what I wanted at the beginning - and still be what he wants...his laundry, cooking, and that [kind of] thing. So I've kind of looked at both roles at the same time. Like on the weekends or whenever I feel like I have to have help, I tell him, “you know you need to do some of this and some of that.” ...But, at the same time, my mom, she tells me, "You know, women are supposed to do these things." So, come to think of it, I do. I fill both roles. That's why it's kind of overwhelming sometimes.

Participant 4: You can do whatever you want. Just know that if you want a career and go to school that's good, that's ok, but the main thing is to be there once you have kids, to provide for your children, to be there to show love to your kids and to teach them the culture and the values, and also to go to school and accomplish what you wanted to do, and being there for your husband or your spouse and to provide that support for them. I think those are pretty much the things I learned from my grandparents and my mom. And that our expectation is to provide nourishment to our kids and then to have two different roles as a mother and to continue our careers in what we want to do. 
Interviewer: Do you ever see any sort of conflict in starting a family?

Participant 16: Yes, because its time. All my friends have kids, every single one, and I have seen them struggle...I think it’s time-management; it’s going to be hard I think. ...it's actually kind of scary.

Participant 6: I have my priorities and stuff that I need to take care of, my school that I have to do and if they need me then they will call me but if I have a test on a certain day then I just tell them that I have a test and that I can't be there. Even though they are important, got to live day by day and pray for them. That's all I can do.

Interviewer: Um how do you manage to be a mom and a student?

Participant 11: I think that some of that is cultural, because in Zuni we're a very a tight community...I lived with my grandparents most of my life, and even now they are a big part of my life because they watch my daughter, but I wouldn’t be here maybe if it wasn’t for my grandma because she does a lot for me. She watches my little girl. And she’s at the age of school age so she is in head start right now. So, I mean it's hard though, because sometimes I don't know what is going on with her and her school. But, I mean we try to juggle. I ask my husband and he helps out. We try to figure out each other's schedules so it is compatible with...everything we are doing.

Participant 2: Basically my role is, when I'm at school, a student. And as soon as classes are over, you know, like right now, my mother instinct’s like “pick up your daughter.” So I got my daughter to pick up from school. Once I get home I just have my basic priorities like clean the house, are they hungry? After all my home duties, I get to my 
homework if I have time. When I'm at home I'm usually just with my kids and doing some homework here on the side. Or as a wife, you know, just being there for laundry, cleaning, stuff like that.

Participant 17: When my cousins were doing their homework, my little cousins, I would do my homework with them. And, I just found it easy to multi-task, and get things done, like family time, mixed in with homework time, and bonding time with my mom on the weekends. I found it quite easy to go to school and be a family person and still have a social life.

Participant 16: It was actually good for me because I worked full time, I worked nine to five everyday so I treat school like that, too, so that really works well for me. I pretty much have breaks after my class and my last class ends everyday at five. I kind of made it like that, too, when I was picking my schedule up because I knew nine to five, nine to five every day, because I didn’t want to go home and be thinking, you know, doing homework at home...I like to keep it separate.

Participant 9: Yeah, the one thing I tell them is don't wait until you are my age to go to school. Do that first and then have your family - that can always come later. I was always been told that when I was younger but I didn’t pay attention.

Participant 2: I think my oldest sister was the first one to really push school on me because she had twins before she finished [high] school... It was a BIG thing that I 
finished high school because I was...the only one that went places. So they didn't really expect - because I wasn't really the type of person that would probably do something like that [i.e. get pregnant]. But it happened, and when they found out they just shot my dreams down. Especially my step, my sister. She gave it to me hard. I mean, man, she didn’t talk to me for two weeks. I was at her house. She cried. When she told me how she really felt, she’s like “I didn’t want you to have a kid before you finished college. I didn’t want that life for you because I know how it is. I wanted you to go out there and live life before you could think of another responsibility, another life. You're young, you shouldn't have done that, you know.”

Participant 16: You get used to seeing your parents have kids when they are younger, like most of the people, well my family didn’t really work, you know what I mean, and you see all your parents and everyone having kids and you think "maybe that is the way to go”, I don’t know I think...it is everything about like, it’s just complicated, I wouldn’t even get into it.

Interviewer: Do you ever see any sort of conflict in starting a family? Participant 16: Yes because its time. All my friends have kids, every single one, and I have seen them struggle and they are single moms, you know what I mean? It's hard. I see them struggling all the time wondering who going to babysit their kids for them, who is going to pick them up at daycare and who is going to drop them off and they have school to go to and then they have to go home and cook. I think it's time management; it's going to be hard I think. Yeah, it's scary; it's actually kind of scary. 
Participant 4: ...It's going to be difficult because there are families that are traditional and there are families who are nontraditional. There is kind of conflict in-between because of the traditional values of the Navajo and there's the Christian values of the Navajo that Navajo people carry also and it conflicts in-between them. I think that with both of my families, because my family and my in-laws' family, there's kind of a conflict between us because my family is traditional and they are not. But then we kind of came up with what we wanted to do to raise our kids.

Participant 2: Well they expect as the daughter -in-law, you're supposed to be in the kitchen helping. As soon as you get done there, whatever they're doing. If you're just sitting out in the car or just sitting in the living room it's like you're still not in the family kind of thing. You're still a stranger and or just even visiting. They get on our butts about that... I noticed that on his side of the family some of their in-laws, they're like that. The new ones that come in, you know, they don't like talk to you, they don’t cook with you, they'll laugh with you, and like, you're an outcast of that family.... 


\section{APPENDIX C:}

\section{GUIDING QUESTIONS}

Indigenous Women College Students’ Perspectives on College, Work and Family Note: The interviews should be conducted in a relatively unstructured manner to facilitate spontaneous, genuine, and open responses. Interviewers will use minimal encouragers and reflective listening to maximize the depth of participant responses. The following questions are samples of ways the interviewers might ask questions. They also are guides to content that is expected to be covered in the interviews.

\section{Guiding Questions}

1. What were your plans and hopes coming in to college? For after school?

2. Tell me a little about your family?

3. Does your tradition have any rules/norms for women in the family? What are they?

4. What do you see as your roles/what are your roles in your family (as a daughter, sister) (Or if married, what were your roles as you grew up)?

5. What will your role be in your future family (wife, mother) (or if married, current family)?

6. How did your family feel about you going to college/university?

7. How did/do you feel about coming to school?

8. What has been/was helpful in making that transition?

9. What do you plan to do when you are done with college/university?

10. Do you plan to have a career? How do you see it playing into your future family life?

11. Do you have any concerns about life after college/university graduation? 


\section{APPENDIX D:}

\section{DEMOGRAPHIC QUESTIONNAIRE}

\section{Demographic Information}

Code ID :

Date:

College/University attending now:

Other Universities/Colleges attended:

Major:

Gender:

Age:

Years in College/University:

Home Community:

Years lived on a reserve/reservation:

High school(s) attended:

Band/Tribal affiliation(s):

Parents' education

Mother:

Father: 


\section{APPENDIX E:}

\section{CONSENT FORMS}

\section{Consent to be a Research Subject}

\section{Introduction}

This research project investigates perspectives of Native American and First Nations female college students on family and career issues. It is being conducted by Dr. Aaron Jackson, Dr. Brian Parry, Dr. Steve Smith, Dr. Caleb Bush, Dr. Louise Alexitch, Jennie Lyn Bingham, Lisa Fox, and Colton Miller (faculty and students at Brigham Young University, the University of New Mexico-Gallup, San Juan College, and the University of Saskatchewan). You were selected to participate because you are a Native American or First Nation student currently enrolled at a postsecondary institution.

\section{Procedures}

You will be asked to fill out a demographic questionnaire and then participate in a one-on-one interview. These measures are not lengthy, and you should expect to be done in less than an hour. Interviews will be audio-taped in order to increase accuracy.

\section{Risks/Discomforts}

Participating in this study will only pose minimal risk to you, although you may experience some emotional discomfort or embarrassment when confronted with culturally sensitive measures. The investigators will be sensitive to those who may become uncomfortable.

\section{Benefits}

There are no known direct benefits to you. However, it is hoped that through your participation, further understanding of the impact that cultural identity, familial values, and career goals will facilitate further success of Native American and First Nation students.

\section{Confidentiality}

All information provided will remain confidential and will only be reported as group data with no identifying information. All data will be kept in a locked case and on password-protected computers available only to those directly involved in the study. At the conclusion of the study, all study material will be destroyed.

\section{Compensation}

You will receive no compensation for your participation in this study.

\section{Participation}

Participation in this study is voluntary. You are free to discontinue your participation at any time. There will be no repercussions to you should you decide not to participate or to withdraw prior to completion. 


\section{Questions about the Research}

If you have questions regarding this study, you may contact Dr. Aaron Jackson at (801) 4228031, aaron_jackson@byu.edu, Louise Alexitch at louise.alexitch@usask.ca or Jennie Lyn Bingham at jennielyn@byu.net.

\section{Questions about your Rights as a Research Participant}

If you have questions regarding your rights as a participant in a research project, you may contact Dr. Christopher Dromey, IRB Chair, at (801) 422-6461, or dromey@byu.edu.

I have read, understood, and received a copy of the above consent and desire of my own free will and volition to participate in this study.

Name (Please Print):

Date:

Signature: 


\section{CONSENT TO PARTICIPATE IN RESEARCH}

\section{INTRODUCTION}

You are invited to participate in a research study conducted by Dr. Caleb Bush, from the department of Social Sciences at the University of New Mexico; Dr. Aaron Jackson, Dr. Steve Smith, Jennie Lyn Bingham, and Colton Miller (faculty and students at Brigham Young University) and Dr. Brian Parry (of San Juan College). You were selected to participate because you are a Native American student currently enrolled at a postsecondary institution.

\section{PURPOSE OF THE STUDY}

This research project investigates perspectives of Native American Female college students on family and career issues.

\section{PROCEDURES AND ACTIVITIES}

You will be asked to fill out a demographic questionnaire and then participate in a one-on-one interview. These measures are not lengthy, and you should expect to be done in less than an hour. Interviews will be audio-taped in order to increase accuracy. You will receive no compensation for your participation in this study.

\section{POTENTIAL RISKS AND DISCOMFORTS}

Participating in this study will only pose minimal risk to you, although you may experience some emotional discomfort or embarrassment when confronted with culturally sensitive measures. The investigators will be sensitive to those who may become uncomfortable.

\section{POTENTIAL BENEFITS TO PARTICIPANTS AND/OR TO SOCIETY}

There are no known direct benefits to you. However, it is hoped that through your participation, further understanding of the impact that cultural identity, familial values, and career goals will facilitate further success of Native American students.

\section{CONFIDENTIALITY}

Any information obtained in connection with this study and that can be identified with you will remain confidential and will be disclosed only with your permission or as required by law. All information provided will remain confidential and will only be reported as group data with no identifying information. All data will be kept in a locked case and on password-protected computers available only to those directly involved in the study. At the conclusion of the study, all study material will be destroyed.

\section{PARTICIPATION AND WITHDRAWAL}

You can choose whether to participate in this study or not. If you volunteer to participate, you may withdraw at any time without penalty or loss of benefits to which you might otherwise be entitled. You may also refuse to answer any questions you do not want to answer and still remain in the study.

\section{IDENTIFICATION OF INVESTIGATORS AND REVIEW BOARD}

If you have any questions or concerns about the research, please feel free to contact: Dr. Aaron Jackson at (801) 422-8031, aaron_jackson@byu.edu or Dr. Caleb Bush at (505) 863-7549, cbush@gallup.unm.edu

If you have other concerns or complaints, contact the Institutional Review Board at the University of New Mexico, 1717 Roma NE, Room 205, Albuquerque, NM 87131, (505) 277-2257, or toll free at 1-866-844-9018. 


\section{SIGNATURE OF RESEARCH PARTICIPANT}

I understand the procedures described above. My questions have been answered to my satisfaction, and I agree to participate in this study. I have been provided a copy of this form.

Name of Participant (please print)

Signature of Participant

Date

\section{SIGNATURE OF INVESTIGATOR}

In my judgment the participant is voluntarily and knowingly providing informed consent and possesses the legal capacity to give informed consent to participate in this research study

Name of Investigtor or Designee

Signature of Investigator or Designee

Date

\section{IRB APPROVAL STAMP}

[Please allow 2 inch space here and at the bottom of each page for the IRB to stamp your consent form with approval and expiration dates.] 


\section{Consent Form: First Nations’ Students Academic and Career Perspectives}

This research project investigates perspectives of First Nations' students on academic and career issues. It is being conducted by Dr. Aaron Jackson, Dr. Brian Parry, Dr. Steve Smith, Dr. Caleb Bush, Dr. Louise Alexitch, Jennie Lyn Bingham, and Colton Miller (faculty and students at Brigham Young University, the University of New Mexico-Gallup, San Juan College, and the University of Saskatchewan). You were selected to participate because you are a First Nation student currently enrolled at a university.

You will be asked to fill out a short demographic questionnaire and then participate in a one-on-one interview. Questions in the interview will concern your experiences as an Aboriginal student attending the University of Saskatchewan, reasons for coming to university, expectations concerning university life and educational goals, and your family and community's expectations of you. The interview will take approximately one hour, and it will be audio-taped in order to increase accuracy.

Your participation in the study is completely voluntary, all information gathered from you will be kept confidential, and results will be reported in a summarized format only. All data will be kept in a locked case and on password-protected computers available only to those directly involved in the study. At the conclusion of the study, all study material will be destroyed.

You may choose to not answer or skip questions, and you can withdraw from the study at any time without academic penalty - that is, your grades will not be affected in any way, and you will still receive a gift certificate for participating.

The study was approved by the University of Saskatchewan's Behavioural Research Ethics Board on October -----, and by the Institutional Review Board at Brigham Young University on November 15, 2007. If you have any questions about the study, please contact either Dr. Louise Alexitch (louise.alexitch@usask.ca, or 966-5922) or Dr. Aaron Jackson (aaron_jackson@byu.edu). Any questions concerning your rights as a participant can be addressed to the Office of Research Services - Ethics Office (306-966-2084). Out of town participants may call collect.

\section{Consent to Participate:}

$\mathrm{I}$, [print your name], have read and understood the description of the research study provided above. I have been provided with an opportunity to ask questions and my questions have been answered satisfactorily. I agree to participate in the study, understanding that I may withdraw my consent to participate at any time, and that there are no anticipated risks. A description of the study and contact information will be given to me for my records.

(Signature of Participant)

(Date)

(Signature of Principal Researcher) 


\section{Consent to Tape-Record Interview:}

$\mathrm{I}$, [print your name] give consent to have this interview tape-recorded for the purposes of accurately, and completely, including my responses in the study. I also understand that I will be given a transcription of the interview approximately one month from now for me to review and approve. At any time during the interview, I can indicate to the interviewer that I no longer wish to have my responses tape-recorded, whereupon I will be give the option of continuing the interview (the interviewer will record my responses manually) or withdrawing my consent to participate in the study. If the latter, all my taped responses will be erased in my presence. Again, there will be no penalty for withdrawing from the study.

(Signature of Participant)

(Date)

Transcript Release: First Nations’ Students Academic and Career Perspectives Thank you again for participating in this project, and for providing us with valuable information!

Before you leave, would you like to read through a written version (transcription) of your interview which should be ready approximately one month from now? This gives you an opportunity to review the transcript for accuracy (Were all your responses to the interview understood correctly?), and it also gives you the chance to change, add, or omit responses - or to even completely withdraw your responses from the study. Even if you choose not to do this, you may still contact the researcher later if you change your mind and want to see the transcription of your interview.

\section{Yes, I would like to review a transcription of my interview.}

Participant's Name:

Telephone Number:

E-Mail Address:

No, I do not want to review a transcription of my interview.

Participant's Name:

Participant's Signature: 


\section{Debriefing Form: First Nations’ Students Academic and Career Perspectives}

For Native American and Canadian post-secondary students, success is a collective experience, and one of the obstacles of success experienced by students is the feeling that they must live in two worlds (Juntunen et al., 2001) - that of their culture and that of the "white campus" (Lin, LaCounte, \& Eder, 1988, p. 13). The academic difficulties and non-persistence of Aboriginal students in the U.S. and Canada are well documented (Ah Nee-Benham \& Stein, 2003; Steward, 1993; U.S. Department of Education, 1998). Despite evidence of academic ability, postsecondary dropout rates are higher for Aboriginal students than for any other minority student groups (Reddy, 1993). One way to explain these results is the demand placed on Aboriginal students to adapt to a different culture when they pursue postsecondary education (Jackson, Smith \& Hill, 2003). In fact, Jackson, Smith, and Hill (2003) found that successful American Indian college students raised on reservations reported that getting through college required them to make adaptation from their culture to a different culture. These same students, however, kept a strong sense of their own culture.

This research project investigates perspectives of First Nations' students on academic and career issues. It is being conducted by Dr. Aaron Jackson, Dr. Brian Parry, Dr. Steve Smith, Dr. Caleb Bush, Dr. Louise Alexitch, Jennie Lyn Bingham, and Colton Miller (faculty and students at Brigham Young University, the University of New Mexico-Gallup, San Juan College, and the University of Saskatchewan). You were selected to participate because you are a First Nation student currently enrolled at a university.

Thank you again for participating in this project, and for providing us with valuable information! If you have any questions about the study or if you would like a copy of the results, please feel free to contact the researchers, either Dr. Louise Alexitch (306-966-5922; louise.alexitch@usask.ca.) or Dr. Aaron Jackson (801-422-8031; aaron_jackson@byu.edu). The study was approved by the University of Saskatchewan's Behavioural Research Ethics Board on October -----, and by the Institutional Review Board at Brigham Young University. Any questions concerning your rights as a participant can be addressed to the Office of Research Services (966-2084). Out of town participants may call collect.

\section{Good luck with all your future plans!}

Dr. Aaron Jackson, Associate Professor

Department of Counseling Psychology, Brigham Young University, Provo, Utah

Dr. Louise R. Alexitch, Associate Professor

Department of Psychology, University of Saskatchewan, Saskatoon, SK. 


\section{DISSERTATION REFERENCES}

Ah Nee-Benham, M. K. P., \& Stein, W. (2003). Forward. In M. K. P. \& W. Stein (Eds.). The Renaissance of American Indian Higher Education: Capturing the Dream. Mahwah, New Jersey: Lawrence Erlbaum.

Alfred P. Sloan Foundation. (2008). Workplace, workforce, and working families: History. Retrieved from http://www.sloan.org/program/32/page/84

Barnett, R., Gareis, K. C., James, J., \& Steele, J. (2003). Planning ahead: College seniors' concerns about career-marriage conflict. Journal of Vocational Behavior, 62(2), 305-319. doi:10.1016/S0001-8791(02)00028-3

Bichsel, R. J., \& Mallinckrodt, B. (2001). Cultural commitment and the counseling preferences and counselor perceptions of Native American women. The Counseling Psychologist, 29(6), 858-881. doi:10.1177/0011000001296007.

Bourassa, C., McKay-McNabb, K., \& Hampton, M. (2004). Racism, sexism, and colonialism: The impact on the health of Aboriginal women in Canada. Canadian Women Studies/Les Cahiers de la Femme, 24(1), 23-30. Retrieved from http://pi.library.yorku.ca/ojs/index.php/cws/article/viewFile/6172/5360

Cinamon, R. (2006). Anticipated Work-Family Conflict: Effects of Gender, Self-Efficacy, and Family Background. The Career Development Quarterly, 54(3), 202-215. Retrieved from EBSCOhost.

Cvetkovich, G., Baumgardner, S., \& Trimble, J. (1984). Social psychology: Contemporary perspectives on people. New York: Holt, Rinehart, \& Winston.

Denzin, N. K., \& Lincoln, Y. S. (2000). The discipline and practice of qualitative research. In N. K. Denzin \& Y. S. Lincoln (Eds.), Handbook of qualitative research (2nd ed., pp. 1-29). 
Thousand Oaks, CA: Sage.

Emslie, C., \& Hunt, K. (2009). 'Live to work' or 'work to live'? A qualitative study of gender and work-life balance among men and women in mid-life. Gender, Work and Organization, 16(1), 151-172. doi:10.1111/j.1468-0432.2008.00434.x

Fouad, N. A., \& Tinsley, H. E. A. (1997). Work-family balance. Journal of Vocational Behavior, 50(2), 141-144. doi:10.1006/jvbe.1996.1579

Freeman, C. \& Fox, M. (2005). Status and trends in the education of American Indians and Alaska Natives (NCES 2005-108). U.S. Department of Education, National Center for Education Statistics. Washington, DC: U.S. Government Printing Office.

Friedman, S., \& Weissbrod, C. (2005). Work and family commitment and decision-making status among emerging adults. Sex Roles, 53(5), 317-325.

Gadamer, H. G. (2004). Truth and method. New York: Seabury Press.

Gregory, A., \& Milner, S. (2009). Editorial: Work-life balance: A matter of choice?. Gender, Work and Organization, 16(1), 1-13. doi:10.1111/j.1468-0432.2008.00429.x

Hallett, M. B., \& Gilbert, L. A. (1997). Variables differentiating university women considering role-sharing and conventional dual-career marriages. Journal of Vocational Behavior, 50(2), 308-322. doi:10.1006/jvbe.1996.1574

Hoshmand, L. T. (1989). Alternate research paradigms: A review and teaching proposal. The Counseling Psychologist, 17(1), 3-79. doi:10.1177/0011000089171001

Indian and Northern Affairs Canada. (2010, Feb 5). First Nations. Retrieved from http://www.ainc-inac.gc.ca/ap/fn/index-eng.asp

Jackson, A. P., \& Patton, M. J. (1992). A hermeneutic approach to the study of values in counseling. Counseling and Values, 36(3), 201-209. Retrieved from EBSCOhost. 
Jackson, A. P., \& Smith, S. A. (2001). Postsecondary transitions among Navajo Indians. Journal of American Indian Education,40(2), 28-47.

Jackson, A. P., Smith, S. A., \& Hill, C. L. (2003). Academic Persistence Among Native American College Students. Journal of College Student Development, 44(4), 548-565. doi:10.1353/csd.2003.0039

Jackson, A. P., \& Turner, S. (2004). Counseling and psychotherapy with Native Americans. In T. Smith (Ed.), Practicing multiculturalism. Boston: Allyn Bacon

Jasper, D. (2004). A short introduction to hermeneutics. Louisville, KY: Westminster John Knox Press.

Johnson, J.A., \& Johnson, M.S. (2008). New city domesticity and the tenacious second shift. Journal of Family Issues, 49(4), 487-515. doi: 10.1177/0192513X07310313

Jones, S. R., \& McEwen, M. K. (2000). A conceptual model of multiple dimensions of identity. Journal of College Student Development, 41(4), 405-414. Retrieved from EBSCOhost.

Juntunen, C. L., Barraclough, D. J., Broneck, C. L., Seibel, G. A., Winrow, S. A., \& Morin, P. M. (2001). American Indian perspectives on the career journey. Journal of Counseling Psychology, 48(3), 274-285. doi:10.1037/0022-0167.48.3.274

Kawulich, B. B. (1998). Muscogee (Creek) women's perceptions of work. Retrieved from Dissertations \& Theses: Full Text database. (Publication No. AAT 9903268).

Kawulich, B. B. (2000). Influence of Skills and Education on Work Choices of Muscogee (Creek) Women. (ERIC Document Reproduction Service No. ED441963) Retrieved from ERIC database.

Kvale, S. (1987). Validity in the qualitative research interview. Methods, 1, 37-72. 
Kvale, S. (1996). Interviewing: An introduction to qualitative research interviewing. Thousand Oaks, CA: Sage.

Kvale, S., \& Brinkmann, S. (2009). InterViews: Learning the Craft of Qualitative Research Interviewing (2nd ed.). Thousand Oaks, CA: Sage.

Lin, R., LaCounte, D., \& Eder, J. (1988). A study of Native American students in a predominantly White college. Journal of American Indian Education, 27, 8-15.

Livingston, M. M., Burley, K., \& Springer, T. P. (1996). The importance of being feminine: Gender, sex role, occupational and marital role commitment, and their relationship to anticipated work-family conflict. Journal of Social Behavior \& Personality, 11(5), 179192. Retrieved from EBSCOhost.

McCloskey, C., \& Mintz, L. (2005) A culturally oriented approach for career counseling with Native American women. In B.W. Walsh, (Ed.), Handbook of Career Counseling for Women (pp. 315-349). Mahwah, NJ: Lawrence Erlbaum Associates, Inc.

Mendelson, M. (2004). Aboriginal People in Canada's Labour Market: Work and Unemployment, Today and Tomorrow. Ottawa: The Caledon Institute of Social Policy.

Milligan, S., \& Bougie, E. (2009, Oct. 28). First Nations women and postsecondary education in Canada: Snapshots from the census. Retrieved from http://www.statcan.gc.ca/pub/81004-X/2009004/article/11017-eng.htm

Napholz, L. (2000). Balancing multiple roles among a group of urban midlife American Indian working women. Health Care for Women International, 21(4), 255-266. doi:10.1080/073993300245122

Packer, M. J. (1985). Hermeneutic inquiry in the study of human contact. American Psychologist, 40(10), 1081-1093. doi:10.1037/0003-066X.40.10.1081. 
Parker, R. A., \& Aldwin C. M. (1994). Desiring careers but loving families: Period, cohort, and gender effects in career and family orientations. Job stress in a changing workforce: Investigating gender, diversity, and family issues. Washington: American Psychological Association: 23-38.

Patton, M. Q. (1990). Qualitative evaluation and research methods (2 ${ }^{\text {nd }}$ ed.). Newbury Park, CA: Sage.

Polkinghorne, D. E. (1991). Generalization and qualitative research: Issues of external validity. Paper presented at the American Educational Research Association Annual Meeting, Chicago.

Polkinghorne, D. E. (1984). Further extensions of methodological diversity for counseling psychology. Journal of Counseling Psychology, 31(4), 416-429. doi: 10.1037/00220167.31.4.416

Reddy, M. A. (Ed.). (1993). Statistical record of native North Americans. Washington, DC: Gale Research.

Reutter, L., Neufeld, A., \& Harrison, M. J. (2000). A review of the research on the health of lowincome Canadian women. CJNR: Canadian Journal of Nursing Research, 32(1), 75-97. Retrieved from EBSCOhost.

Rudy, R. M., Popova, L., \& Linz, D. G. (2010). The context of current content analysis of gender roles: An introduction to a special issue. Sex Roles, 62(11-12), 705-720. doi:10.1007/s11199-010-9807-1

Sabelis, I., Nencel, L., Knights, D., \& Odih, P. (2008). Editorial: Questioning the construction of 'balance': A time perspective on gender and organization. Gender, Work and Organization, 15(5), 423-429. doi:10.1111/j.1468-0432.2008.00411.x 
Schnittker, J. (2007). Working more and feeling better: Women's health, employment, and family life, 1974-2004. American Sociological Review, 72(2), 221-238. doi:10.1177/000312240707200205

Schwandt, T. A. (2000). Three epistemological stances for qualitative inquiry. In N. K. Denzin \& Y. S. Lincoln (Eds.), Handbook of qualitative research (2nd ed., pp. 189-213). Thousand Oaks, CA: Sage.

Schwandt, T. A. (2007). The sage dictionary of qualitative inquiry ( $3^{\text {rd }}$ ed.). Thousand Oaks, CA: Sage.

Shepard, B., O'Neill, L., \& Guenette, F. (2006). Counselling with First Nations women: considerations of oppression and renewal. International Journal for the Advancement of Counselling, 28(3), 227-240. doi:10.1007/s10447-005-9008-8

Sue, D.W., \& Sue, D. (1999). Counseling the culturally different: theory and practice (3rd ed.). New York: J. Wiley \& Sons.

Steward, R.J. (1993). Two faces of academic success: Case studies of American Indians on a predominantly Anglo university campus. Journal of College Student Development, 34, 191-196.

Thomason, T. C. (1999). Improving the recruitment and retention of Native American students in psychology. Cultural Diversity and Ethnic Minority Psychology, 5(4), 308-316. doi:10.1037/1099-9809.5.4.308

U.S. Bureau of Labor Statistics. (2011, March). BLS spotlight on statistics: Women at work. Retrieved from http://www.bls.gov/spotlight/2011/women/pdf/women_bls_spotlight.pdf U.S. Department of Education. (1998). American Indians and Alaska Natives in postsecondary education. Washington, DC: U.S. Government Printing Office. 
U.S. Department of Labor. (2007). Employment status of women and men in 2007. Retrieved from http://www.dol.gov/wb/factsheets/Qf-ESWM07.htm

Weer, C. H., Greenhaus, J. H., Colakoglu, S., \& Foley, S. (2006). The role of maternal employment, role-altering strategies, and gender in college students' expectations of work-family conflict. Sex Roles, 55(7-8), 535-544. doi:10.1007/s11199-006-9107-y 